\title{
Role of Nitric Oxide in the Regulation of Renin and Vasopressin Secretion
}

\author{
IAN A. REID \\ Department of Physiology, University of California, San Francisco, \\ San Francisco, California 94143-0444
}

\begin{abstract}
Research during recent years has established nitric oxide as a unique signaling molecule that plays important roles in the regulation of the cardiovascular, nervous, immune, and other systems. Nitric oxide has also been implicated in the control of the secretion of hormones by the pancreas, hypothalamus, and anterior pituitary gland, and evidence is accumulating that it contributes to the regulation of the secretion of renin and vasopressin, hormones that play key roles in the control of sodium and water balance. Several lines of evidence have implicated nitric oxide in the control of renin secretion. The enzyme nitric oxide synthase is present in vascular and tubular elements of the kidney, particularly in cells of the macula densa, a structure that plays an important role in the control of renin secretion. Guanylyl cyclase, a major target for nitric oxide, is also present in the kidney. Drugs that inhibit nitric oxide synthesis generally suppress renin release in vivo and in vitro, suggesting a stimulatory role for the L-arginine/nitric oxide pathway in the control of renin secretion. Under some conditions, however, blockade of nitric oxide synthesis increases renin secretion. Recent studies indicate that nitric oxide not only contributes to the regulation of basal renin secretion, but also participates in the renin secretory responses to activation of the renal baroreceptor, macula densa, and beta adrenoceptor mechanisms that regulate renin secretion. Histochemical and immunocytochemical studies have revealed the presence of nitric oxide synthase in the supraoptic and paraventricular nuclei of the hypothalamus and in the posterior pituitary gland. Colocalization of nitric oxide synthase and vasopressin has been demonstrated in some hypothalamic neurons. Nitric oxide synthase activity in the hypothalamus and pituitary is increased by maneuvers known to stimulate vasopressin secretion, including salt loading and dehydration. Administration of $\mathrm{L}$-arginine and nitric oxide donors in vitro and in vivo has variable effects on vasopressin secretion, but the most common one is inhibition. Blockade of nitric oxide synthesis has been reported to increase vasopressin secretion, but again variable results have been obtained. An attractive working hypothesis is that nitric oxide serves a neuromodulatory role as an inhibitor of vasopressin secretion. KEY WORDS: Nitric oxide; nitric oxide synthase; renin secretion; vasopressin secretion; kidney; hypothalamus. . 1994 Academic Press. Inc.
\end{abstract}

\section{INTRODUCTION}

An enormous amount of research performed during recent years has established nitric oxide as a unique and important signaling molecule involved in cell-to-cell communication and other functions throughout the body (for reviews see $8,10,63,70,77,111,128$ ). It is now known that nitric oxide plays important 
roles in the cardiovascular, nervous, renal, and immune systems, but increasing evidence indicates that its functions extend well beyond those systems. For example, nitric oxide appears to play an important role in the regulation of endocrine function, having been implicated in the control of the secretion of hormones by the pancreas, hypothalamus, and anterior pituitary gland $(24,25$, $45,61,98,107,115)$. Evidence is also accumulating that nitric oxide contributes to the regulation of the secretion of renin and vasopressin, hormones that play key roles in the control of sodium and water balance. The purpose of this review is to summarize recent progress concerning the role of nitric oxide in the secretion of these two hormones.

\section{THE L-ARGININE/NITRIC OXIDE PATHWAY}

The L-arginine/nitric oxide pathway is shown in Fig. 1. Nitric oxide is formed from the terminal guanidino group of L-arginine by the enzyme nitric oxide synthase $(8,63,77)$. Three distinct isoforms of nitric oxide synthase have been identified and their cDNA has been cloned and sequenced $(38,63,65,78)$. In humans, the isoforms are encoded by three different genes each located on

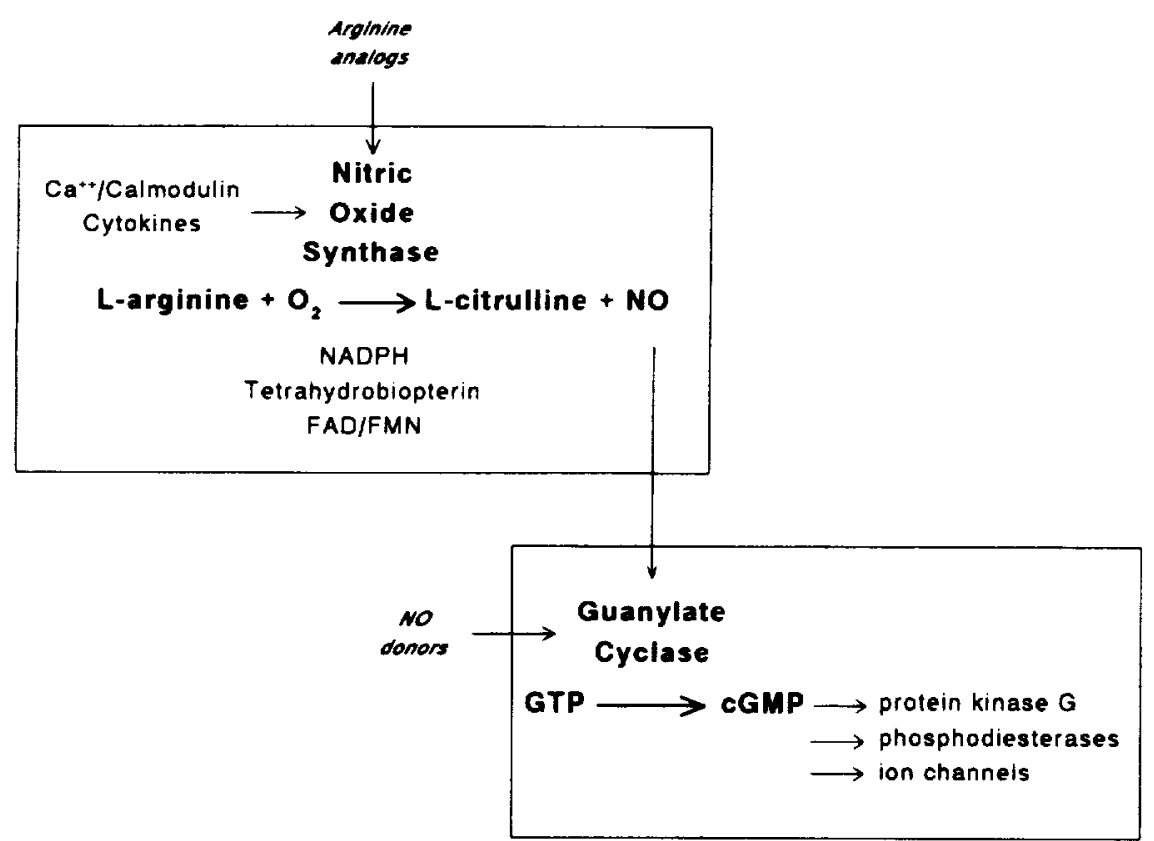

FIG. 1. The L-arginine/nitric oxide/cyclic GMP signaling pathway. Constitutive isoforms of nitric oxide synthase (Types I and II) require calcium/calmodulin for activity; Type III nitric oxide synthase is expressed after induction by cytokines and other substances. Each isoform can be inhibited by a variety of arginine analogs. 
different chromosomes. Each isoform contains heme at its active site and all require the cofactors $\mathrm{NADPH}$, tetrahydrobiopterin, flavin adeninedinucleotide, and flavin mononucleotide.

Type I nitric oxide synthase (also referred to as bNOS and nNOS) was originally identified in neurons and is distributed widely in the brain and autonomic nervous system. It is expressed constitutively and is activated by calcium bound to calmodulin. Type II nitric oxide synthase (iNOS) is expressed in macrophages, smooth muscle, and the liver after induction by bacterial lipopolysaccharide or cytokines. Expression of this isoform requires protein synthesis, but enzyme activity is not dependent on calcium. Type III nitric oxide synthase (eNOS) was originally identified in endothelial cells but it has also been found in kidney epithelial cells. Like Type I nitric oxide synthase, it is expressed constitutively and is activated by calcium/calmodulin. Type III nitric oxide synthase is responsible for endothelium-dependent relaxation of vascular smooth muscle.

Nitric oxide is quite diffusible, but is rapidly inactivated with a half-life of approximately $5 \mathrm{~s}$ and is thought to function primarily in a paracrine or autocrine fashion. A major target for nitric oxide is soluble guanylyl cyclase (34). Nitric oxide binds to iron in the heme at the active site of guanylyl cyclase, altering the conformation of the enzyme and thereby increasing its activity. Stimulation of guanylyl cyclase activity by nitric oxide in turn results in increased formation of cyclic guanosine $3^{\prime}, 5^{\prime}$-monophosphate (cyclic GMP) whose targets include phosphodiesterases, ion channels, and a cyclic GMP-dependent protein kinase that mediates smooth muscle relaxation.

\section{Nitric Oxide Synthase and Guanylyl Cyclase in the Kidney}

The presence of Type I nitric oxide synthase in the kidney has been demonstrated by immunocytochemistry and NADPH histochemistry $(69,79,119$, 129). The presence of Type I nitric oxide synthase mRNA has also been demonstrated by in situ hybridization (79) and the polymerase chain reaction (118). By these methods, abundant nitric oxide synthase has been demonstrated in the macula densa (Fig. 2). This is of particular interest in view of the important role of this structure in the control of renin secretion. Type I nitric oxide synthase is also present in other tubular and vascular elements of the kidney $(69,118)$. An inducible form of nitric oxide synthase is present in smooth muscle and granular cells of the terminal afferent arteriole (119). Finally, Type III nitric oxide synthase has been identified in LLC-PK $\mathrm{P}_{1}$ kidney epithelial cells (122).

Soluble guanylyl cyclase, a major target for nitric oxide (Fig. 1), is widely distributed in the kidney in the glomerulus, renal tubules, and vascular system (118). Intrarenal administration of inhibitors of nitric oxide decreases cyclic GMP release $(11,113)$, while the nitric oxide donor sodium nitroprusside increases it (51). 


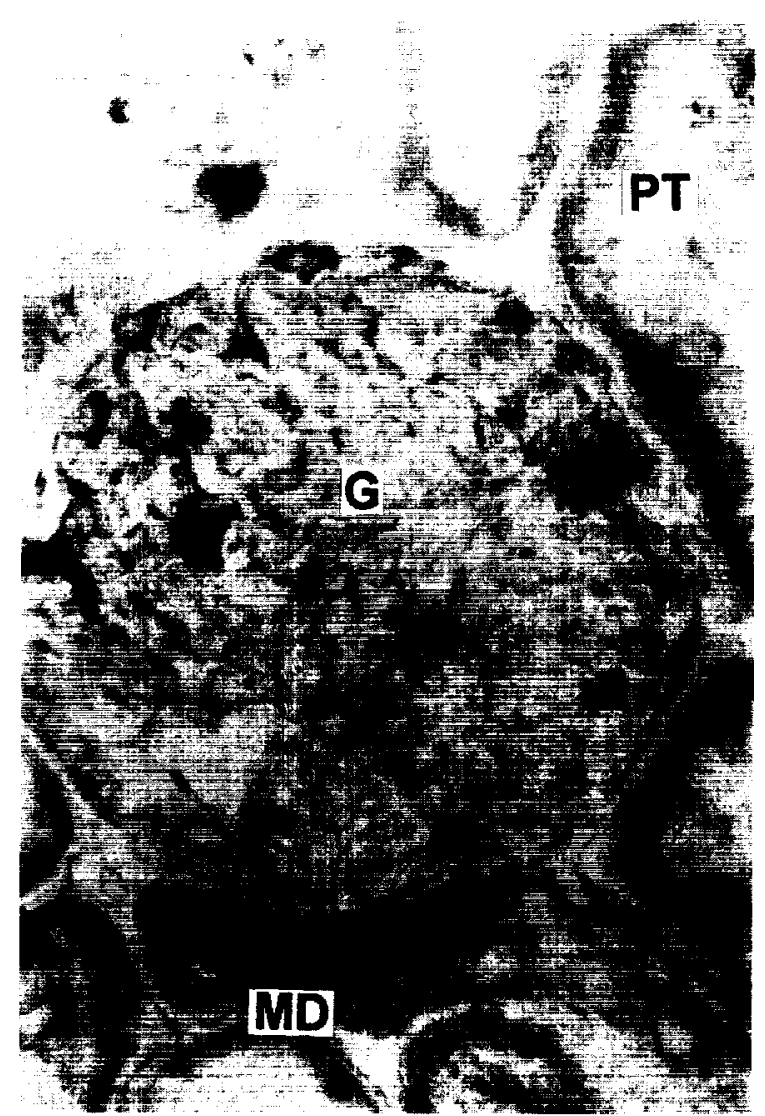

FIG. 2. NADPH diaphorase staining of rabbit kidney. G, glomerulus; MD, macula densa; PT, proximal tubule; DT.

These observations demonstrate that nitric oxide is synthesized in the kidney where it acts to stimulate the formation of cyclic GMP.

\section{Drugs Used to Investigate the L-Arginine/Nitric Oxide Pathway}

Investigation of the function of the L-arginine/nitric oxide pathway has been greatly facilitated by the availability of several groups of drugs $(63,89)$ (Table 1 ). Of particular importance is a group of $L-N^{\omega}{ }^{\omega}$-substituted arginine analogs that are competitive inhibitors of nitric oxide synthase. These inhibitors appear to be specific for nitric oxide synthase, although it has been reported that some may block muscarinic receptors (12). The inactive D-enantiomers of these arginine analogs are also available and serve as useful controls. Several drugs serve as nitric oxide donors; their action is not blocked by nitric oxide synthase inhibi- 
TABLE 1

Examples of Drugs Used to Investigate the L-Arginine/Nitric Oxide Pathway

\begin{tabular}{lll}
\hline \multicolumn{1}{c}{ Name } & Abbreviation & Action \\
\hline L-arginine & L-Arg & NO precursor \\
$N^{\omega}$-monomethyl-L-arginine & L-NMMA & NOS inhibitor \\
$N^{\omega}$-nitro-t-arginine & L-NNA & NOS inhibitor \\
$N^{\omega}$-nitro-1-arginine methyl ester & L-NAME & NOS inhibitor \\
Sodium nitroprusside & & NO donor \\
3 -Morpholinosydnonimine & SIN-1 & NO donor \\
$S$-Nitroso- $N$-acetyl-D,L-penicillamine & SNAP & NO donor \\
Hemoglobin & & NO scavenger \\
\hline
\end{tabular}

tors. Finally, hemoglobin can be used as a nitric oxide scavenger. These drugs have all been used to investigate the role of nitric oxide in the regulation of renin and vasopressin secretion.

\section{ROLE OF NITRIC OXIDE IN THE REGULATION OF RENIN SECRETION}

\section{Control of Renin Secretion}

The rate at which renin is secreted by the juxtaglomerular cells in the afferent arteriole of the kidneys is the major determinant of the activity of the reninangiotensin system, and the mechanisms that regulate renin secretion have been studied extensively during the past three decades $(28,46,55,62,114,124)$. Three major regulatory mechanisms have been identified and extensively, although not completely, characterized. Several other factors including prostacyclin and adenosine participate in the regulation of renin secretion; these may be regulatory mechanisms in their own right or may serve as modulators of the major control mechanisms.

Renin secretion is controlled by the renal baroreceptor, the macula densa, and the sympathetic nervous system. In addition, angiotensin II exerts an important negative feedback action on renin secretion.

\section{Renal Baroreceptor}

The renal baroreceptor monitors renal perfusion pressure and signals an increase in renin secretion when perfusion pressure decreases $(28,46,62)$. This is a sensitive mechanism, and according to one analysis (46), renin secretion doubles with every $2-3 \mathrm{~mm} \mathrm{Hg}$ reduction in renal artery pressure below a threshold of approximately $90 \mathrm{~mm} \mathrm{Hg}$. The pressure sensor appears be located in the afferent arteriole. It may be located in the juxtaglomerular cells themselves, although recent studies failed to provide evidence for this (104). 


\section{Macula Densa}

The macula densa serves as an $\mathrm{NaCl}$ sensor which signals an increase in renin secretion when the amount of $\mathrm{NaCl}$ delivered to the distal nephron decreases $(28,46,62,124)$. This mechanism involves an $\mathrm{Na}^{+}-\mathrm{K}^{+}-2 \mathrm{Cl}^{-}$cotransporter located in the luminal membrane of the macula densa cells $(9,68,106)$. At the present time, the signaling pathway between the macula densa and the juxtaglomerular cells is not known. Several substances have been proposed for this role, including prostacyclin and adenosine $(46,55,114)$. Nitric oxide may also play a role and this possibility is discussed later in this review.

\section{Sympathetic Nervous System}

Norepinephrine released from renal sympathetic nerves stimulates renin secretion by way of beta adrenoceptors thought to be located on the juxtaglomerular cells $(28,46,62,95)$. Most evidence indicates that the stimulation of renin secretion is mediated by activation of adenylate cyclase and the formation of cyclic adenosine $3^{\prime}, 5^{\prime}$-monophosphate (cyclic AMP). Reflex increases in renal sympathetic nerve activity stimulate renin secretion, while reductions in nerve activity suppress it.

\section{Signal Transduction}

The signal transduction mechanisms involved in the control of renin secretion have been studied extensively $(20,22,29,55,66,114)$. Two established intracellular messengers are calcium and cyclic AMP. Calcium constitutes a major inhibitory signal to renin secretion, and the increase in renin secretion that results from activation of the renal baroreceptor is thought to be mediated by a decrease in calcium concentration in the juxtaglomerular cells. Cyclic AMP is another important intracellular messenger molecule which, as noted above, mediates the renin secretory response to beta adrenoceptor stimulation.

Cyclic GMP has also been implicated in the regulation of renin secretion (46, 66,114 ). This is particularly relevant to the present review because nitric oxide is a potent stimulator of guanylyl cyclase activity. However, the role of cyclic GMP remains an enigma, evidence having been presented that cyclic GMP stimulates, inhibits, or has no effect on renin secretion $(46,50,66,85,114)$. Additional research is required to clarify the role of cyclic GMP in the regulation of renin secretion.

\section{Nitric Oxide and the Control of Renin Secretion}

Studies utilizing renal cortical slices, isolated juxtaglomerular cells, and perfused kidneys have implicated endothelial factors in the control of renin secre- 
tion $(16,67,80,125)$. Subsequent studies revealed that one of these factors is nitric oxide. As discussed above, the enzyme nitric oxide synthase and its mRNA are present in the kidney, particularly in cells of the macula densa, a structure that plays an important role in the control of renin secretion. Arginine analogs that inhibit nitric oxide synthesis have been demonstrated to cause alterations in renin secretion when administered to intact animals, perfused kidneys, or renal tissue in vitro.

It now appears that nitric oxide not only contributes to the regulation of basal renin secretion, but is also involved in the renin secretory responses to activation of the major mechanisms that regulate renin secretion.

\section{Basal Renin Secretion}

Several investigators have studied the effect of blocking nitric oxide synthesis on basal renin secretion. In many studies, acute blockade of nitric oxide synthesis has resulted in suppression of renin secretion $(21,27,31,43,57-59,112)$ (Fig. 3). The mechanisms responsible for this suppression of renin secretion

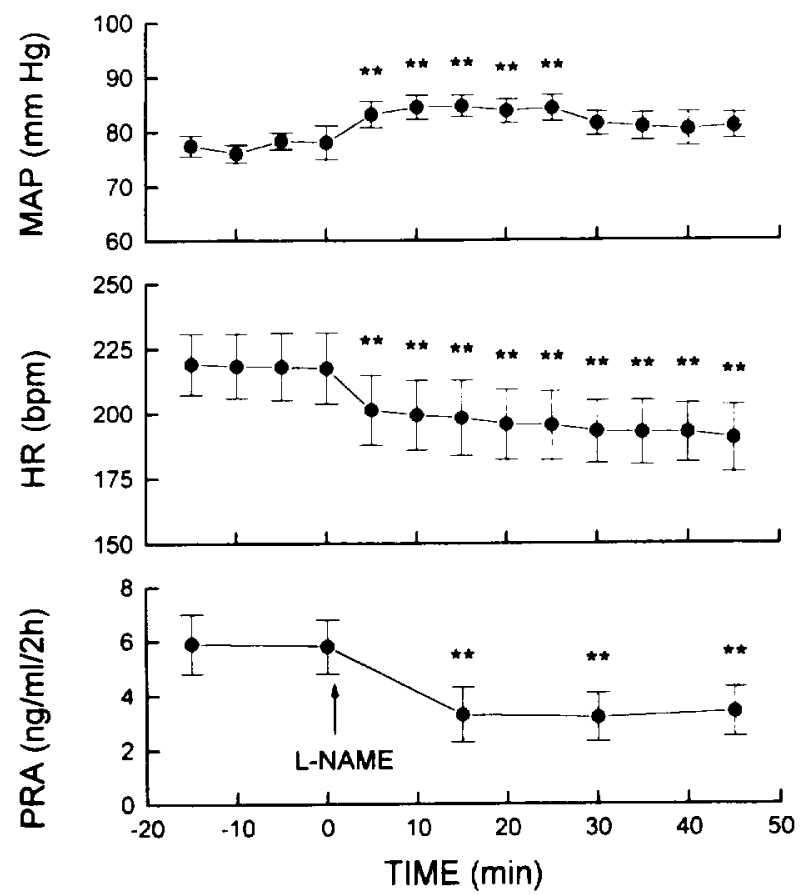

FIG. 3. Effects of the nitric oxide synthase inhibitor L-NAME on mean arterial pressure (MAP), heart rate (HR), and plasma renin activity (PRA). L-NAME $(5 \mathrm{mg} / \mathrm{kg}$ ) was injected intravenously at 0 min. Each point represents the mean \pm SEM of observations made in five conscious rabbits. ${ }^{* *} p<0.01$ compared to the 0 min value. 
have not been conclusively identified. Blockade of nitric oxide synthesis in the intact animal generally increases arterial pressure and this could conceivably suppress renin secretion by increasing renal perfusion pressure or by causing a reflex decrease in renal sympathetic nerve activity. Studies by Sigmon et al. (112) provided support for such a pressure-dependent mechanism. They showed that the suppression of renin secretion elicited by the nitric oxide synthase inhibitor $N^{\omega}{ }^{\omega}$-nitro-L-arginine methyl ester (L-NAME, Table 1) in anesthetized rats could be prevented by maintaining renal perfusion pressure constant and blocking beta adrenoceptor effects on renin secretion with propranolol.

In marked contrast, Johnson and Freeman $(57,59)$ observed that controlling renal perfusion pressure did not prevent L-NAME-induced suppression of renin secretion in anesthetized rats. Moreover, these investigators (59) reported that surgical denervation of the kidneys also failed to prevent the suppression of renin secretion, whether or not renal perfusion pressure was held constant. The reason for the discrepancy between the results of Sigmon et al. and those of Johnson and Freeman is not apparent. Whatever the reason, it is clear that inhibition of nitric oxide synthesis can suppress renin secretion in the absence of the renal nerves and changes in renal perfusion pressure. For example, infusion of nitric oxide synthase inhibitors in isolated rat kidneys inhibits renin release even when the kidneys are perfused at constant pressure $(41,42,80)$. Moreover, it has been reported that inhibition of nitric oxide synthesis increases rather than decreases renal sympathetic nerve activity $(47,100)$.

It is known that inhibition of nitric oxide synthesis can produce marked alterations in renal hemodynamics and tubular function $(3,30,32,52,53,72,88$, 102) which could in turn cause alterations in renin secretion. However, inhibition of nitric oxide synthesis suppresses renin release by isolated juxtaglomerular cells cocultured with endothelial cells $(67,110)$ where such changes could not be involved. Similarly, the nitric oxide precursor L-arginine and the nitric oxide donors sodium nitroprusside and SIN-1 (Table 1) both stimulate renin release in vitro $(26,110)$.

How then does inhibition of nitric oxide synthesis suppress renin secretion? One possibility is that the inhibition results from an increase in cyclic AMP metabolism by phosphodiesterase. It is now known that there are several isoforms of phosphodiesterase, one of which (PDE III) is inhibited by cyclic GMP $(4,23)$. As discussed above, nitric oxide donors increase renal cyclic GMP levels, and this would be expected to inhibit PDE III, decrease cyclic AMP hydrolysis, and increase renin secretion. Our recent observation that the PDE III inhibitor milrinone increases resting renin secretion in rabbits (93) (Fig. 4) is consistent with this proposal. Conversely, inhibition of nitric oxide synthesis would decrease renal cyclic GMP levels, resulting in disinhibition of PDE III, increased cyclic AMP hydrolysis, and suppression of renin release. Our finding that milrinone prevents the suppression of renin secretion by L-NAME (92) provides support for such a mechanism. The possible role of PDE III is discussed in more detail below in the section on nitric oxide and beta adrenoceptor control of renin secretion. 


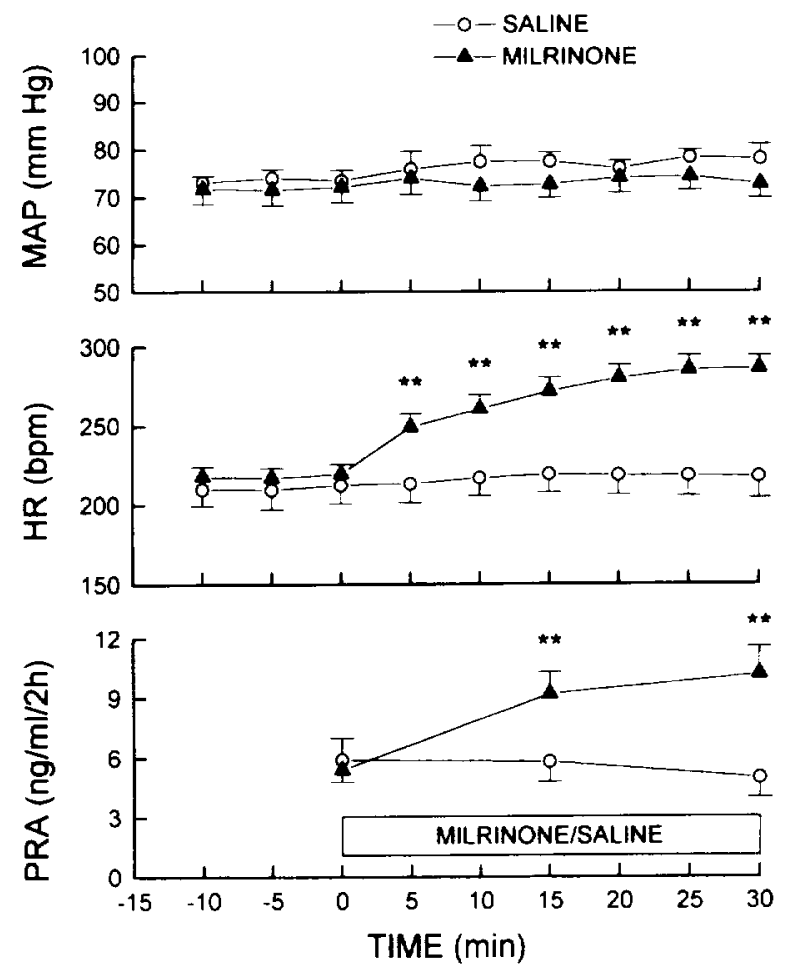

FIG. 4. Effects of the phosphodiesterase III inhibitor milrinone on mean arterial pressure (MAP), heart rate (HR), and plasma renin activity (PRA). Milrinone $(10 \mu \mathrm{g} / \mathrm{kg} / \mathrm{min}$ ) or the saline vehicle was infused intravenously from 0 to $30 \mathrm{~min}$. Each point represents the mean \pm SEM of observations made in 12 conscious rabbits. ${ }^{* *} p<0.01$ compared to the 0 min value.

In other studies, blockade of nitric oxide synthesis has been found to increase renin secretion. For example, chronic administration of nitric oxide synthase inhibitors increased plasma renin activity in rats (97) and dogs (101). Nitric oxide synthase inhibitors also increased renin release when infused intrarenally in dogs (117) or when added to renal cortical slices in vitro (5). The reason that inhibition of nitric oxide synthesis decreases renin secretion in some circumstances but increases it in others is not clear. Schricker and Kurtz (109) have proposed that nitric oxide can exert both inhibitory and stimulatory actions on renin secretion, but additional investigation is required.

In summary, studies of the effects of inhibition of nitric oxide on renin secretion in several laboratories have clearly implicated nitric oxide in the control of basal renin secretion. In most circumstances, inhibition of nitric oxide synthesis suppresses renin secretion. The accompanying changes in blood pressure or renal function may contribute to the suppression in vivo, but other mechanisms must be involved because the suppression also occurs in vitro. Changes in cyclic AMP metabolism may be involved. In other circumstances, for 
example, long-term treatment, inhibition of nitric oxide synthesis increases renin secretion. Further study of these changes in renin secretion and of the mechanisms underlying them is needed.

\section{Pressure-Dependent Renin Secretion}

The renin secretory response to a decrease in renal perfusion pressure is thought to be mediated by a reduction in calcium concentration in the juxtaglomerular cells $(22,66)$. Since nitric oxide decreases calcium concentration in vascular smooth muscle and other cells, an interaction between nitric oxide and the pressure control of renin secretion would be anticipated. Several groups of investigators have now provided evidence for a role of nitric oxide in pressuredependent renin release.

Persson et al. (86) investigated the effect of inhibiting nitric oxide synthesis on pressure-dependent renin release in conscious dogs. They assessed the renin secretory response to step reductions in renal artery pressure to $50 \mathrm{~mm} \mathrm{Hg}$ under control conditions and following intravenous administration of L-NAME. The results are shown in Fig. 5. L-NAME markedly attenuated pressuredependent renin secretion, especially in the low pressure range, without significantly altering the autoregulation of renal blood flow and glomerular filtration rate.

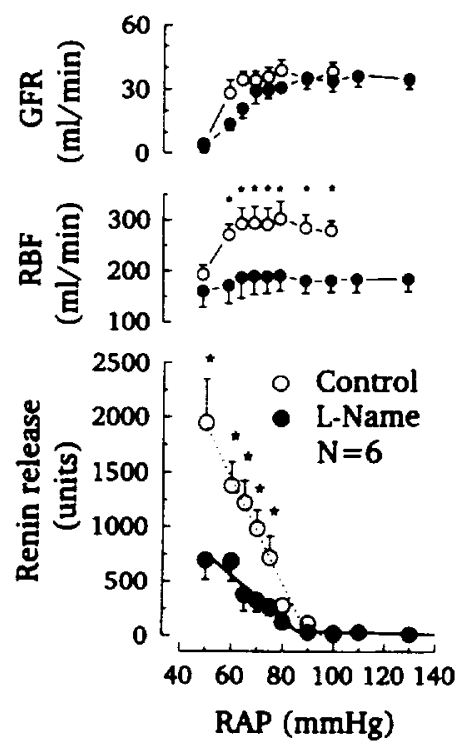

FIG. 5. Glomerular filtration rate (GFR), renal blood flow (RBF), and renin release during step reductions in renal artery pressure (RAP) before and after administration of the nitric oxide synthase inhibitor L-NAME in conscious dogs. Reproduced with permission from Persson et al. (86). 
Although the results of Persson $e t$ al. clearly demonstrate that inhibition of nitric oxide synthesis suppresses the renin response to renal hypotension, it is important to note that L-NAME was administered intravenously in a dose which caused a marked pressor response. Thus, it could be argued that the suppression of the renin response resulted from a systemic effect of inhibition of nitric oxide synthesis. For example, a reduction in renal sympathetic nerve activity could be responsible as suggested by Sigmon et al. (112). On the other hand, Naess et al. (82) observed that intrarenal infusion of another nitric oxide synthase inhibitor L-NNA in anesthetized dogs, in a dose that did not alter systemic arterial pressure, markedly suppressed the renin response to constriction of the renal artery.

Additional evidence for an intrarenal site of action of nitric oxide synthase inhibitors on renin secretion was provided by Scholz and Kurtz (108). They observed that the renin response to reduction in renal artery pressure in isolated rat kidneys was markedly attenuated by three inhibitors of nitric oxide synthesis. Evidence was provided that this attenuation was specifically due to a reduction in nitric oxide formation. These investigators also observed that acetylcholine, a known stimulus to nitric oxide formation (70), enhanced the renin response to reductions in renal perfusion pressure, particularly at low perfusion pressures.

These studies clearly demonstrate that there is an interaction between nitric oxide and pressure-dependent renin release. However, the source of this nitric oxide and the mechanisms by which it influences pressure-dependent renin release remain to be determined.

\section{Beta Adrenoceptor Control of Renin Secretion}

Although there is evidence that nitric oxide participates in the vasodilator response to beta adrenoceptor stimulation $(44,127)$, there is little information concerning possible interactions between nitric oxide and the beta adrenoceptor control of renin secretion. Sigmon et al. (112) investigated the effect of L-NAME in propranolol-treated anesthetized rats in which renal perfusion pressure was held constant. In these circumstances, L-NAME increased renin secretion. They proposed that L-NAME caused a stimulation of renin secretion that was counteracted by a reflex reduction in beta adrenoceptor stimulation of renin secretion in response to the systemic effects of L-NAME. The possibility that there is an interaction between nitric oxide and the beta adrenoceptor control of renin secretion at the level of the kidney was not considered. However, subsequent studies by Scholz and Kurtz (108) failed to provide evidence for such an interaction. They found that blockade of nitric oxide synthesis in a perfused rat kidney preparation did not alter the renin secretory response to beta adrenoceptor stimulation with isoproterenol. Only two kidneys were studied and results were presented for only one of these.

In order to further investigate a possible role of nitric oxide in beta adrenocep- 
tor control of renin secretion, we studied the effect of inhibiting nitric oxide synthesis with L-NAME on the renin secretory response to beta adrenoceptor stimulation with isoproterenol in conscious rabbits (91). The results are summarized in Fig. 6. Infusion of isoproterenol alone increased plasma renin activity and heart rate. Pretreatment with L-NAME reduced the heart rate response to isoproterenol and inhibited the renin response. The renin and heart rate responses could be partially or fully restored by administration of the nitric oxide donor nitroprusside, providing evidence that the effects of L-NAME were due to inhibition of nitric oxide synthesis. These findings provide evidence that nitric oxide participates in the renin secretory and heart rate responses to beta adrenoceptor stimulation. Moreover, the finding that the renin and heart rate responses to isoproterenol could be restored by nitroprusside indicates that the responses are not mediated by nitric oxide, but that the presence of nitric oxide is required in order for the responses to be manifested.

There are several possible mechanisms by which inhibition of nitric oxide synthesis could attenuate the renin secretory response to isoproterenol. LNAME increases arterial pressure and this could inhibit the renin response to isoproterenol by activating the renal baroreceptor mechanism or by causing a reflex reduction in renal sympathetic nerve activity. However, the pressor effect of L-NAME in our experiments was small $(6-10 \mathrm{~mm} \mathrm{Hg})$ and during infusion of isoproterenol, mean arterial pressure was not significantly higher in the presence of L-NAME than in its absence (Fig. 6). Furthermore, we have found that administration of the same dose of L-NAME in conscious rabbits causes little or no reduction in renal sympathetic nerve activity ( $\mathrm{K}$. Kumagai and I. A. Reid, unpublished observations), and others have reported that inhibition of nitric oxide synthesis in anesthetized rats increases rather than decreases renal sympathetic nerve activity $(47,100)$. Nevertheless, to investigate if the pressor action of L-NAME could be responsible for the attenuation of the renin response to isoproterenol, we tested the effect of producing a similar increment in blood pressure with an infusion of phenylephrine. The results are summarized in Fig. 7. Phenylephrine produced the same increase in blood pressure as L-NAME, but did not significantly alter the renin or heart rate responses to isoproterenol. Thus, it is unlikely that the pressor effect of L-NAME was responsible for the suppression of the renin response to isoproterenol.

As discussed above, it is now generally accepted that the renin secretory response to isoproterenol is mediated by beta adrenoceptors coupled to adenylate cyclase and the generation of cyclic AMP. It was therefore of interest that Klabunde et al. (64) reported that the increase in cardiac cyclic AMP concentration induced by isoproterenol was reduced by the nitric oxide synthase inhibitor L-NMMA. They also observed that L-NMMA decreased cardiac cyclic GMP concentration and suggested that this resulted in disinhibition of the cyclic GMP-inhibitable isoform of cyclic AMP phosphodiesterase (PDE III) which in turn increased hydrolysis of cyclic AMP. As shown in Fig. 8, a similar mechanism could explain the suppression of the renin response to isoproterenol.

Central to the scheme proposed in Fig. 8 is the enzyme PDE III. This enzyme 

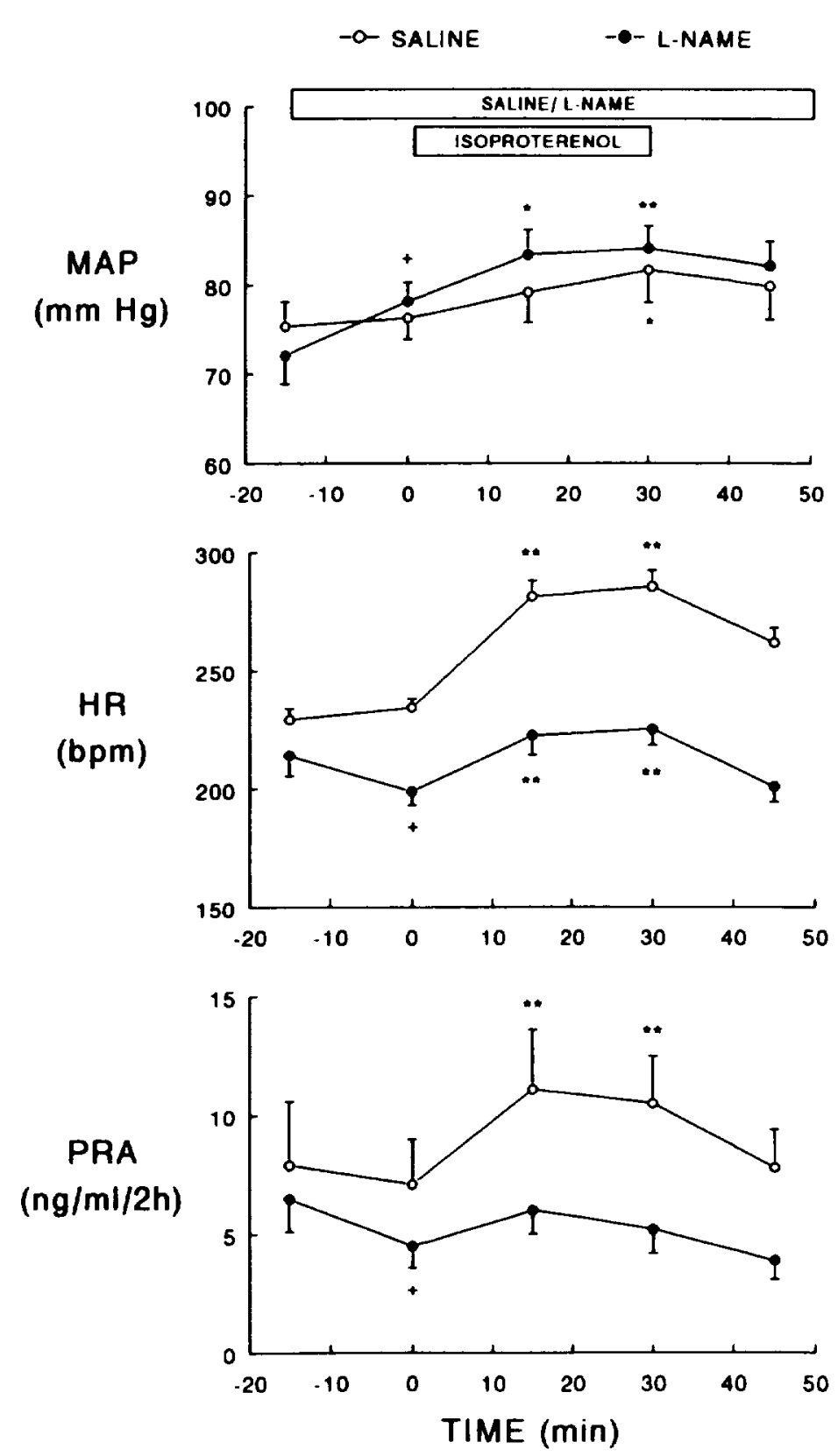

FIG. 6. Effects of intravenous isoproterenol infusion on mean arterial pressure (MAP), heart rate (HR), and plasma renin activity (PRA) during intravenous infusion of L-NAME or the saline vehicle. Infusion of $\mathrm{L}-\mathrm{NAME}(0.5 \mathrm{mg} / \mathrm{kg} / \mathrm{min})$ or the saline vehicle was started immediately after completion of control measurements at $-15 \mathrm{~min}$ and continued throughout the experiment. Isoproterenol $(0.02 \mu \mathrm{g} / \mathrm{kg} / \mathrm{min})$ was infused from 0 to $30 \mathrm{~min}$. Values represent the mean $\pm \mathrm{SEM}$ of observations made in eleven conscious rabbits. $+p<0.05$ compared to the -15 min value. ${ }^{*} p<0.05,{ }^{*} p<0.01$ compared to the 0 min value. Slightly modified from Reid et al. (91) 

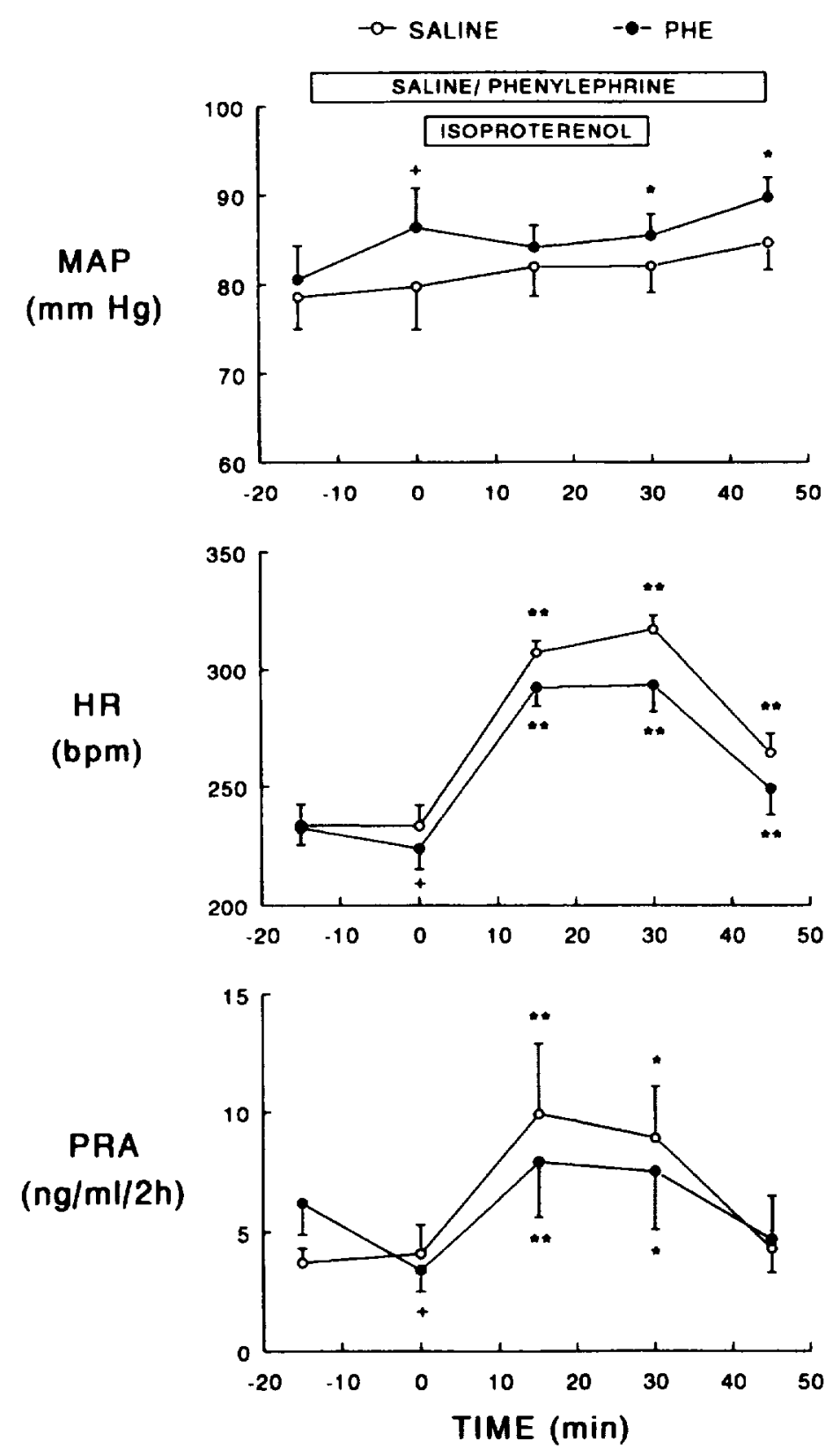

FIG. 7. Effects of intravenous isoproterenol infusion on mean arterial pressure (MAP), heart rate (HR), and plasma renin activity (PRA) during intravenous infusion of phenylephrine or the saline vehicle. Infusion of phenylephrine $(0.5-2.0 \mu \mathrm{g} / \mathrm{kg} / \mathrm{min})$ or the saline vehicle was started immediately after completion of control measurements at $-15 \mathrm{~min}$ and continued throughout the experiment. Isoproterenol $(0.02 \mu \mathrm{g} / \mathrm{kg} / \mathrm{min})$ was infused from 0 to $30 \mathrm{~min}$. Values represent the mean \pm SEM of observations made in eight conscious rabbits. $+p<0.05$ compared to the -15 min value. ${ }^{*} p<0.05,{ }^{* *} p<0.01$ compared to the 0 min value. 


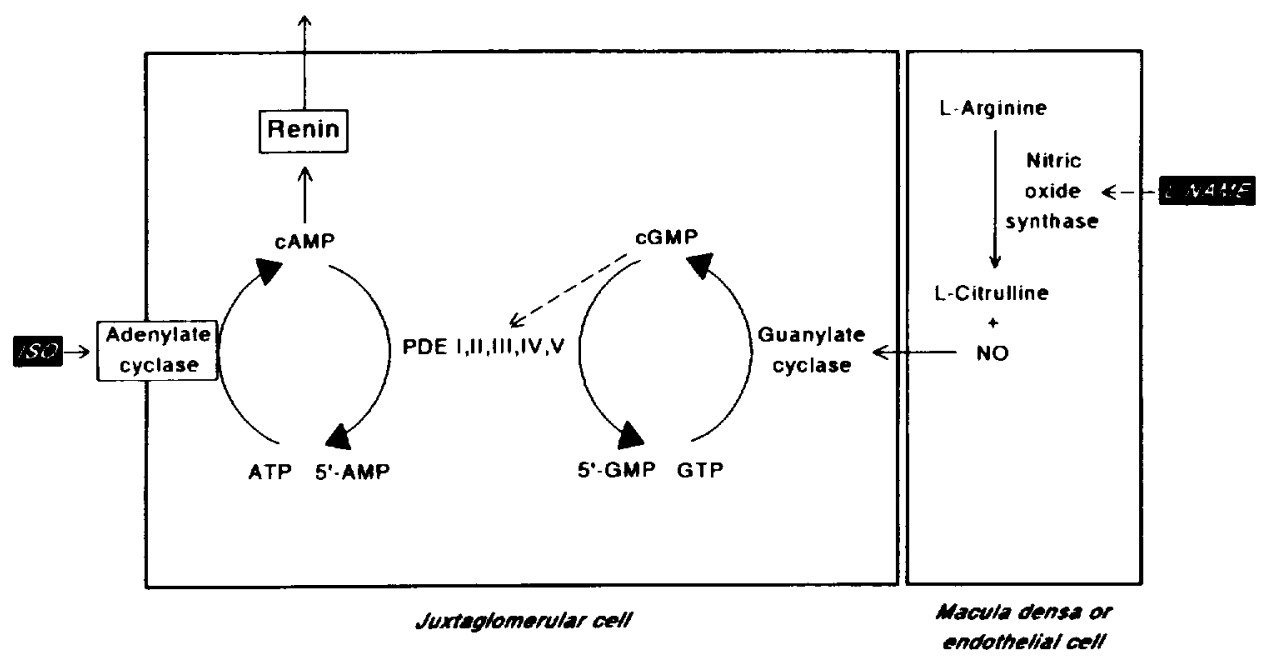

FIG. 8. Hypothetical mechanism by which inhibition of nitric oxide synthesis with L-NAME could suppress the renin secretory response to beta adrenoceptor stimulation with isoproterenol (ISO). According to this hypothesis, L-NAME decreases nitric oxide synthesis in the vicinity of the juxtaglomerular cells. As a result, soluble guanylyl activity and cyclic GMP concentration in the juxtaglomerular cells decrease. The inhibition of the cyclic GMP-inhibitable phosphodiesterase (PDE III) is removed, and hydrolysis of cyclic AMP increases. Consequently, both basal renin secretion and the renin response to ISO decrease. Broken arrow indicates inhibition.

contributes to cyclic AMP hydrolysis in the pulmonary circulation, heart, smooth muscle, adipose tissue, and platelets $(48,81,84)$. PDE III is present in the kidney (74), but it is not known if it participates in the regulation of cyclic AMP concentration in, and renin secretion by, the juxtaglomerular cells. If PDE III does participate in the regulation of the renin secretion, it would be predicted that inhibition of the enzyme would increase renin secretion and potentiate the renin secretory response to beta adrenoceptor stimulation.

Recently, we tested this prediction in conscious rabbits using the specific PDE III inhibitor milrinone (93). As shown in Fig. 4, infusion of milrinone increased renin secretion without changing blood pressure. Milrinone also potentiated the renin response to intravenous infusion of isoproterenol. In this context, it is of interest that Downing et al. (33) have reported that inhibition of PDE III potentiates beta-adrenoceptor-dependent secretion of prorenin by human placental explants. Finally, milrinone inhibited the suppression of renin secretion in response to infusion of L-NAME. This last observation suggests that the suppression of renin secretion by L-NAME results from disinhibition of PDE III and an increase in cyclic AMP hydrolysis in the juxtaglomerular cells. However, measurements of renal cyclic AMP and cyclic GMP levels are needed to test the proposal more directly.

In summary, our results provide evidence that there is an interaction between nitric oxide and the beta adrenoceptor control of renin secretion. Our results also suggest that this interaction involves changes in cyclic AMP hydrolysis by the cyclic GMP-inhibitable isoform of cyclic AMP phosphodiesterase. 


\section{Macula Densa Control of Renin Secretion}

The presence of a high concentration of nitric oxide synthase in the macula densa has stimulated interest in the possibility that nitric oxide is involved in the macula densa control of renin secretion. He et al. (49) investigated the effect of arginine and the nitric oxide synthase inhibitor L-NNA on renin release by an isolated rabbit juxtaglomerular apparatus preparation. Addition of arginine to the tubular lumen increased renin secretion, while addition of L-NNA markedly reduced the renin responses to changes in macula densa $\mathrm{NaCl}$ concentration. The results provide evidence that nitric oxide, possibly originating in the macula densa, can act as a stimulatory factor in the control of renin secretion.

Recently, we investigated the effect of inhibiting nitric oxide synthesis with L-NAME on the renin secretory response to administration of the diuretic furosemide in conscious rabbits (94). Most evidence indicates that furosemide, when administered acutely, stimulates renin secretion by an action on the macula densa. In vivo, the stimulation of renin secretion occurs without decreases in blood volume or blood pressure $(39,75)$ and is not prevented by beta adrenoceptor blockade $(39,56)$. In vitro, furosemide stimulates renin secretion by microdissected afferent arterioles with the macula densa attached but not from afferent arterioles alone (54). Recent evidence indicates that the stimulation of renin secretion by furosemide results from inhibition of $\mathrm{Na}^{+}-\mathrm{K}^{+}-2 \mathrm{Cl}^{-}$ cotransport in the macula densa $(9,19,68,106)$.

The results of our experiments are shown in Fig. 9. Before L-NAME, there were significant increases in plasma renin activity 15,30 , and $45 \mathrm{~min}$ after furosemide; following administration of L-NAME; however, there was only a small increase at $15 \mathrm{~min}$. In control experiments, infusion of phenylephrine in a dose that produced the same increase in arterial pressure as L-NAME did not inhibit the renin response to furosemide. Based on these results, we proposed that L-NAME inhibits the renin response to furosemide by blocking nitric oxide synthesis in the kidney. These results are consistent with those of $\mathrm{He}$ et al. (49) and with the hypothesis that nitric oxide participates in the macula densa control of renin secretion.

How could the L-arginine/nitric oxide pathway in the macula densa participate in the control of renin secretion? More specifically, do alterations in $\mathrm{Na}^{+}-\mathrm{K}^{+}$$2 \mathrm{Cl}^{-}$cotransport alter macula densa nitric oxide synthase activity and, if so, do the resulting changes in nitric oxide synthesis affect renin secretion?

With regard to the first question, it is known that the constitutive forms of nitric oxide synthase require calcium for activity $(38,65)$, and there is evidence that a reduction in macula densa $\mathrm{NaCl}$ concentration increases cytosolic free calcium concentration in cells of the macula densa (103). Thus, it would be anticipated that a decrease in $\mathrm{Na}^{+}-\mathrm{K}^{+}-2 \mathrm{Cl}^{-}$cotransport would increase nitric oxide synthase activity in the macula densa. To test this prediction, we investigated the effect of administration of furosemide on nitric oxide synthase activity in the macula densa. In these experiments, rabbits received an intravenous injection of furosemide $(20 \mathrm{mg} / \mathrm{kg})(n=3)$ or the saline vehicle $(n=3)$. After 30 

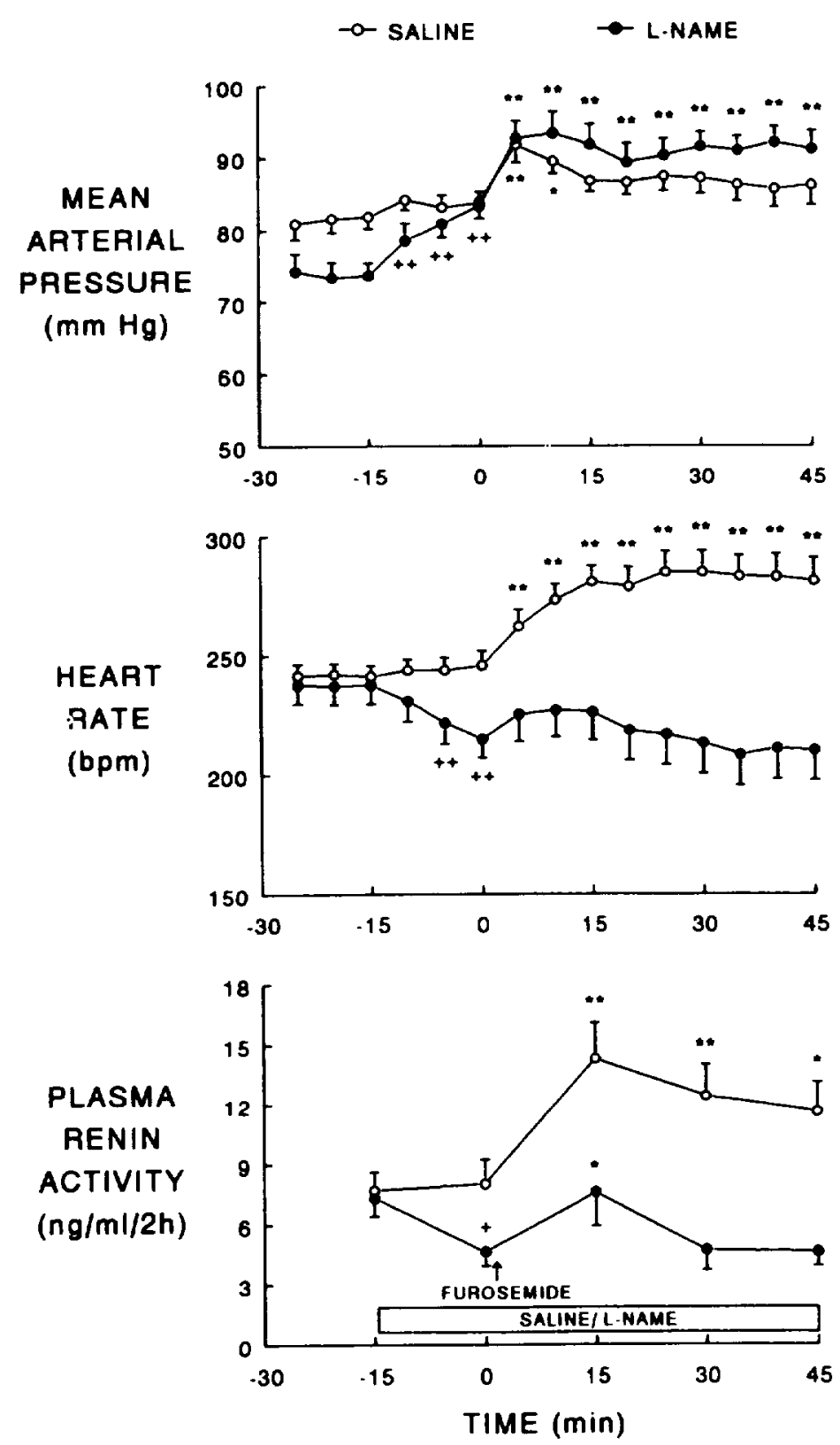

FIG.9. Effect of intravenous furosemide on mean arterial pressure, heart rate, and plasma renin activity during intravenous infusion of L-NAME or the saline vehicle. Intravenous infusion of L-NAME $(0.5 \mathrm{mg} / \mathrm{kg} / \mathrm{min})$ or the saline vehicle was started immediately after completion of control measurements at $-15 \mathrm{~min}$ and continued throughout the experiment. Furosemide $(2 \mathrm{mg} / \mathrm{kg})$ was injected at $0 \mathrm{~min}$. Note that the maximum renin response to administration of L-NAME occurs within the first $15 \mathrm{~min}$ (see (91) and Fig. 3). Values represent the mean \pm SEM of observations made in 12 conscious rabbits. $+p<0.05,++p<0.01$ compared to the -15 min value. ${ }^{*} p<0.05$, ${ }^{* *} p<0.01$ compared to the 0 min value. 
min, the kidneys were removed and processed for NADPH diaphorase histochemistry. Representative kidney sections from control and furosemide-treated rabbits are shown in Fig. 10. There was a clear increase in staining intensity in macula densas of furosemide-treated rabbits. Since, as noted above, furosemide inhibits $\mathrm{Na}^{+}-\mathrm{K}^{+}-2 \mathrm{Cl}^{-}$cotransport in the macula densa, these results are consis-
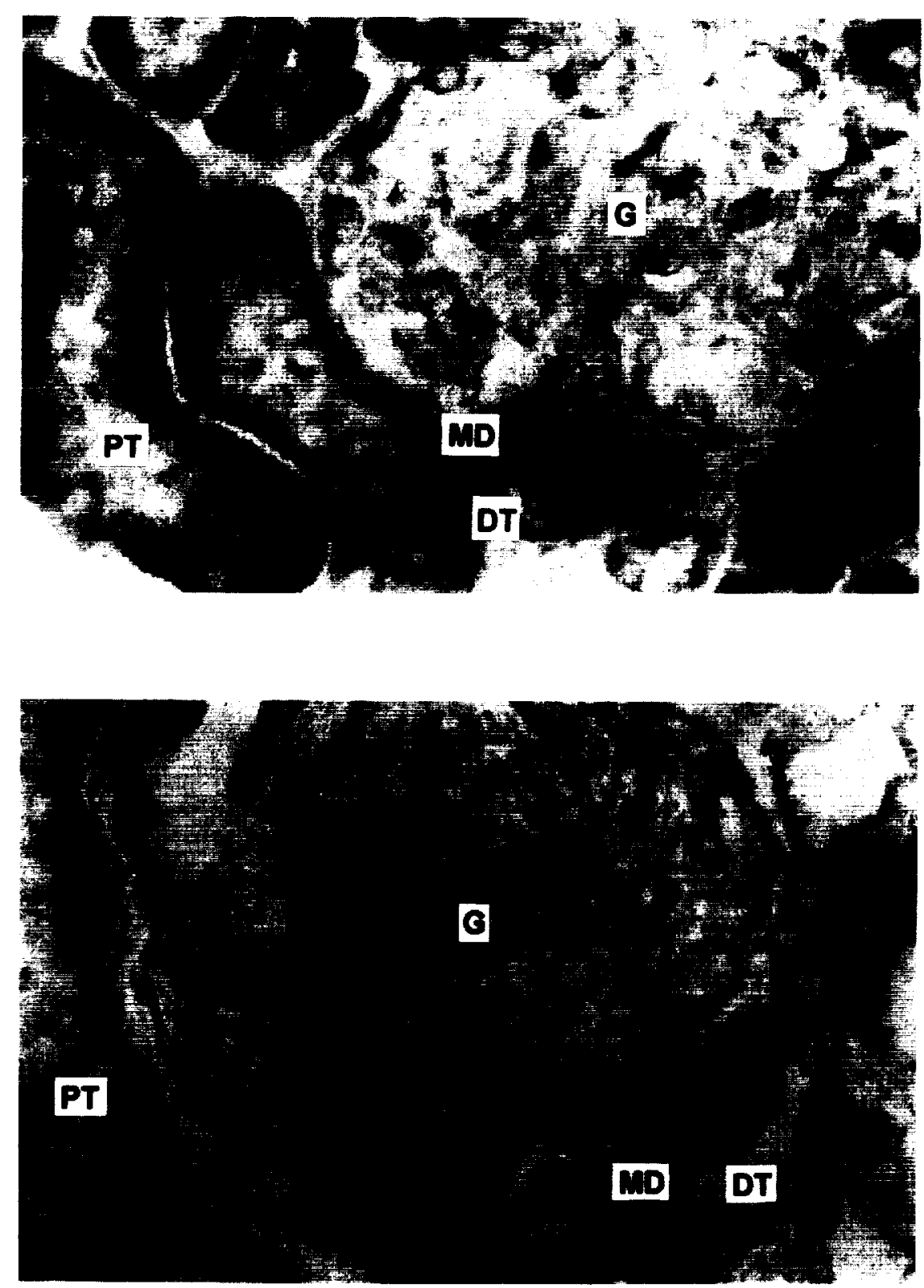

FIG. 10. NADPH diaphorase staining of sections of kidneys from control (top) and furosemidetreated (bottom) rabbits. G, glomerulus, MD, macula densa; PT, proximal tubule; DT, distal tubule. 
tent with the proposal that a reduction in macula densa $\mathrm{NaCl}$ transport increases nitric oxide synthase activity in the macula densa.

With regard to the second question, it is possible that nitric oxide generated in the macula densa diffuses into the adjacent juxtaglomerular cells where it could increase cyclic GMP concentration which, in turn, could stimulate renin secretion, possibly by decreasing the intracellular calcium concentration. The problem here is that while many studies indicate that nitric oxide and/or cyclic GMP stimulate renin secretion, others suggest that these substances inhibit or have no effect on renin secretion $(46,50,66,85,114)$. As noted earlier, this issue needs to be resolved.

The results of a recent study by Tsukahara et al. (123) are particularly relevant to the hypothesis that nitric oxide participates in the macula densa regulation of renin secretion. These investigators observed that a reduction in ambient chloride concentration caused an increase in cytosolic calcium concentration and a calcium/calmodulin-dependent increase in nitric oxide production in cultured rat mesangial cells. They proposed that this nitric oxide could serve to link changes in macula densa ion transport to changes in afferent arteriolar resistance and renin secretion. As they pointed out, nitric oxide released by mesangial cells could augment nitric oxide produced by macula densa cells.

If a reduction in macula densa $\mathrm{NaCl}$ transport increases nitric oxide synthesis, it might be anticipated that the converse would be true. Studies by other investigators $(31,120)$ indicate that dietary salt loading increases, rather than decreases, renal nitric oxide production. However, the site in the kidney at which this increase in nitric oxide production occurs remains to be determined.

Of course, it is important to point out that although our results are consistent with a role for nitric oxide in the macula densa control of renin secretion, they by no means prove it. It is possible, for example, that the action of L-NAME to suppress the renin secretory response to furosemide results from blockade of nitric oxide synthesis in cells other than those of the macula densa such as mesangial (123), endothelial, or other cells. Nevertheless, the fact that there is abundant nitric oxide synthase in the macula densa together with our observation that the activity of this enzyme is apparently increased by furosemide warrants additional investigation of the role of the macula densa L-arginine/ nitric oxide pathway in the regulation of renin secretion.

\section{Summary: Renin}

Several lines of evidence implicate nitric oxide in the control of renin secretion. Nitric oxide synthase is present in vascular and tubular elements of the kidney, particularly in cells of the macula densa, a structure that plays an important role in the control of renin secretion. Guanylyl cyclase, a major target for nitric oxide is also present in the kidney. Drugs that inhibit nitric oxide synthesis generally suppress renin release both in vivo and in vitro, suggesting a stimulatory role for the L-arginine/nitric oxide pathway in the control of renin secretion. Under some conditions, however, nitric oxide apparently inhibits renin secretion. It 
now appears that nitric oxide not only contributes to the regulation of basal renin secretion, but also participates in the renin secretory responses to activation of the renal baroreceptor, macula densa, and beta adrenoceptor mechanisms that regulate renin secretion.

\section{ROLE OF NITRIC OXIDE IN THE REGULATION OF VASOPRESSIN SECRETION}

\section{Biosynthesis and Secretion of Vasopressin}

Vasopressin is synthesized in magnocellular neurons in the supraoptic and paraventricular nuclei of the hypothalamus. It is packaged into secretory granules and transported to the posterior pituitary, where it is stored in nerve terminals and released into the systemic circulation.

The release of vasopressin is controlled by osmotic and reflex mechanisms (40). Stimuli to vasopressin secretion including water deprivation and salt loading act predominantly by way of central osmoreceptors thought to be located in a circumventricular organ, the organum vasculosum of the lamina terminalis. Other stimuli including hypovolemia and hypotension act by way of arterial baroreceptors located in the carotid sinus and aortic arch, and stretch receptors located in the left and right atria. Vasopressin secretion is also stimulated by anesthetics and other pharmacological agents, stress, pain, nausea and vomiting, and angiotensin II.

\section{Nitric Oxide Synthase in the Hypothalamus and Pituitary}

Sagar and Ferriero (99) first demonstrated that magnocellular neurons of the supraoptic and paraventricular nuclei of the rat hypothalamus, the sites of vasopressin synthesis, stain positively for NADPH diaphorase. Their observation was subsequently confirmed by other investigators using both light $(1,13$, $14,60,87,105$ ) and electron (15) microscopy. Sagar and Ferriero (99) also observed strong diaphorase staining in the posterior pituitary, the site of vasopressin storage and secretion; lighter staining was observed in the intermediate and anterior lobes.

Bredt et al. (7) localized nitric oxide synthase protein in the rat brain by immunocytochemistry using antisera raised against the purified enzyme. They observed intense staining of cell bodies in the supraoptic and paraventricular nuclei and in nerve fibers and terminals in the posterior lobe of the pituitary (Fig. 11). As reported by Sagar and Ferriero (99), only weak staining was observed in the intermediate and anterior lobes. Subsequently, Bredt and his associates demonstrated the presence of the mRNA for nitric oxide synthase in supraoptic magnocellular neurons (6). They also showed that nitric oxide synthase and NADPH diaphorase are colocalized throughout the brain.

Calka and Block (14) and Sandez et al. (105) compared the distribution of vasopressin and NADPH diaphorase in the rat hypothalamus using immunocy- 

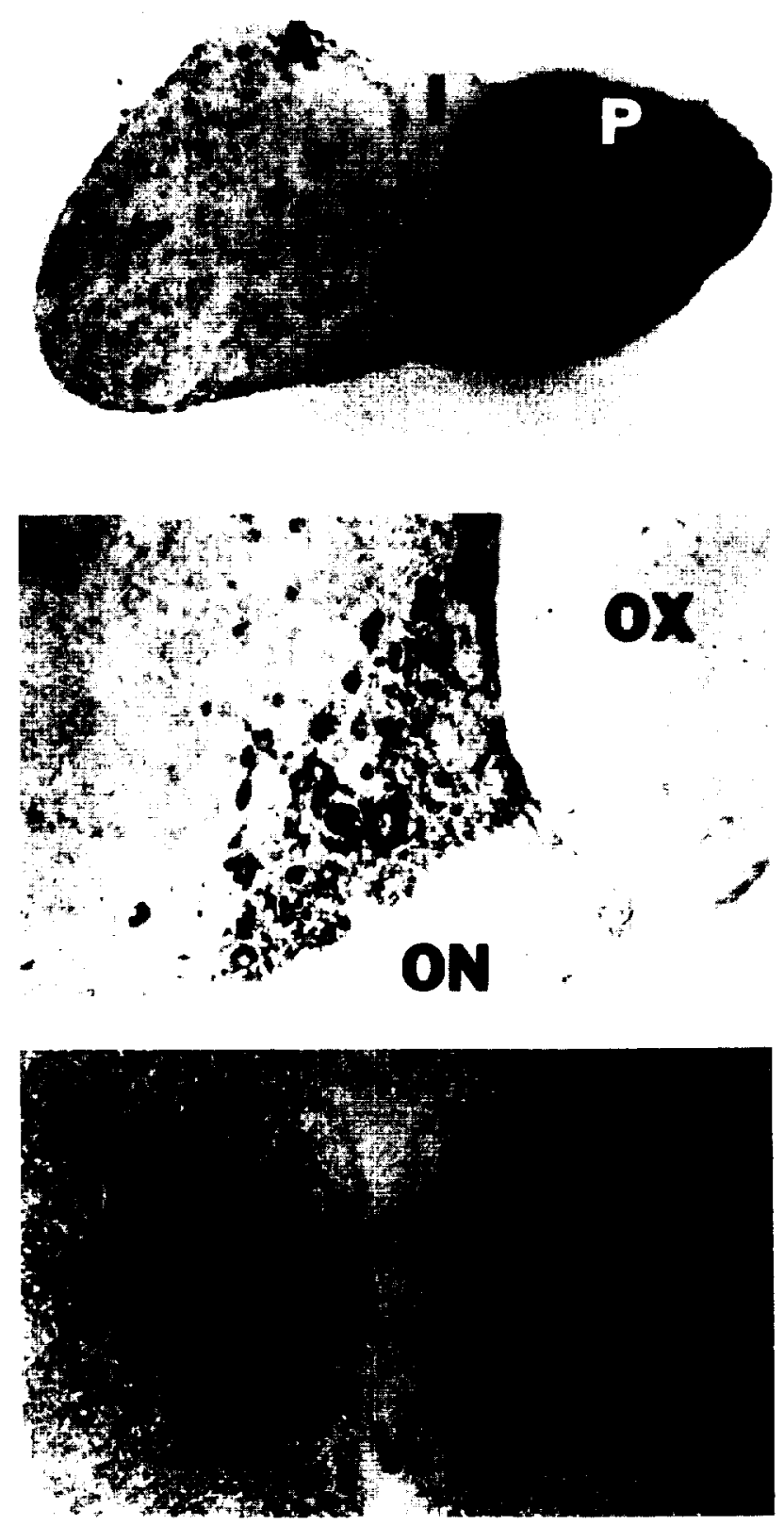

FIG. 11. Immunohistochemical localization of nitric oxide synthase in the pituitary (top), supraoptic nucleus (center), and paraventricular nucleus (bottom). A, anterior lobe; I, intermediate lobe; $\mathrm{P}$, posterior lobe; SO, supraoptic nucleus; $\mathrm{OX}$, optic chiasm; $\mathrm{ON}$, optic nerve; $\mathrm{V}$, third ventricle. Reproduced with permission from Bredt et al. (7). 
tochemistry and histochemistry. Double labeling of a small number of neurons was observed in the supraoptic and paraventricular nuclei. Other investigators have observed colocalization of vasopressin and NADPH in these nuclei, although only a small number of neurons $(76,121)$. Interestingly, colocalization of oxytocin with NADPH occurs more frequently $(76,121)$ and this observation, together with other evidence $(17,116)$, suggests a role for nitric oxide in the control of oxytocin secretion.

Recently, Villar et al. (126) reported that nitric oxide synthase immunoreactivity and mRNA levels in magnocellular neurons of the supraoptic and paraventricular nuclei of rats increase after hypophysectomy. Since there is evidence that nitric oxide participates in the regulation of hypothalamic portal blood flow (18), Villar $e t$ al. reasoned that increased nitric oxide production after damage to neurosecretory axons might increase portal blood flow and promote regeneration of the neural lobe.

\section{Effects of Changes in Salt and Water Balance on Hypothalamic and Pituitary NADPH Activity}

Alterations in sodium and water balance have been observed to cause changes in NADPH activity in the hypothalamus and/or posterior pituitary. Sagar and Ferriero (99) reported that 8 days of salt loading in rats increased NADPH diaphorase activity in the posterior pituitary, but not in the hypothalamus. Pow (87) reported that "dehydration of rats for $12 \mathrm{~h}$ " caused a large and rapid increase in diaphorase staining in the supraoptic nucleus. Calka et al. (15) localized NADPH diaphorase in the rat supraoptic nucleus by electron microscopy. They observed no significant change in mitochondrial diaphorase staining after $12 \mathrm{~h}$ of dehydration, but a "noticeable increase" after 9 days.

These observations demonstrate that nitric oxide synthase is present in the supraoptic and paraventricular nuclei and the posterior pituitary gland, that it can be colocalized with vasopressin, and that its activity can be altered by changes in salt and water balance.

\section{Nitric Oxide and Vasopressin Release: In Vitro Studies}

Recent in vitro studies have provided evidence for a role of nitric oxide in the control of vasopressin release. Yasin et al. (130) studied the effects of nitric oxide donors on basal and stimulated vasopressin release by hypothalamic explants. The nitric oxide precursor $\mathrm{L}$-arginine reduced $\mathrm{KCl}$-evoked vasopressin release and this effect was reduced by the nitric oxide synthase inhibitor L-NMMA as well as by ferrous hemoglobin. L-arginine also reduced interleukin-1 $\beta$-stimulated vasopressin release. The nitric oxide donors SIN-1 and sodium nitroprusside (Table 1) both attenuated $\mathrm{KCl}$-evoked vasopressin release.

Lutz-Bucher and Koch (71) investigated the effect of changes in nitric oxide synthesis on vasopressin release from the isolated neural lobe of the rat pituitary gland. Blockade of nitric oxide synthesis with L-NAME, or inactivation of nitric 
oxide with ferrous hemoglobin, increased vasopressin release. L-arginine, but not D-arginine, and SIN-1 dampened the release of vasopressin evoked by L-NAME.

These two in vitro studies suggest that nitric oxide plays an inhibitory role in the control of vasopressin release and that this action is exerted both at the level of the hypothalamus and pituitary.

\section{Nitric Oxide and Vasopressin Release: In Vivo Studies}

Well before the importance of nitric oxide in the brain was first appreciated, Eriksson et al. (37) investigated the effect of infusing L-arginine into a lateral cerebral ventricle of hydrated goats. They observed that L-arginine caused a decrease in free water clearance in association with an increase in urinary vasopressin excretion. Another basic amino acid, L-lysine, was inactive. Inasmuch as L-arginine is the endogenous precursor of nitric oxide, these observations suggest that nitric oxide can stimulate vasopressin release in vivo. Obviously, however, the effect of a nitric oxide synthase inhibitor on the responses to L-arginine needs to be tested.

In subsequent in vivo studies, the role of nitric oxide in the control of vasopressin secretion has been investigated in rats, rabbits, and dogs.

Rat

Ota et al. (83) observed that intracerebroventricular injection of the nitric oxide donor SNAP (Table 1) in conscious, chronically prepared rats caused transient dose-related increases in plasma vasopressin concentration. Injection of L-arginine also increased plasma vasopressin concentration. In control experiments, injection of $N$-acetylpenicillamine, the inactive precursor of SNAP, or $D$-arginine elicited only very small increases in plasma vasopressin concentration. Based on these results, it was concluded that nitric oxide inhibits vasopressin secretion.

On the other hand, Summy-Long et al. (116) were unable to demonstrate a role for nitric oxide in the secretion of vasopressin during dehydration. They observed that intracerebroventricular injection of two inhibitors of nitric oxide synthase in rats following $24 \mathrm{~h}$ water deprivation failed to alter plasma vasopressin concentration, although there was an increase in plasma oxytocin concentration.

Recent studies by Kadowaki et al. (60) suggest that endogenous nitric oxide exerts an inhibitory action on vasopressin secretion. These investigators studied the effect of salt loading on nitric oxide synthase and vasopressin gene expression in the rat hypothalamohypophyseal system. Salt loading is a potent stimulus to vasopressin secretion which results in marked depletion of vasopressin from the posterior pituitary. During 4 days of salt loading, there were marked increases in nitric oxide synthase (Fig. 12) and vasopressin mRNA levels, and 


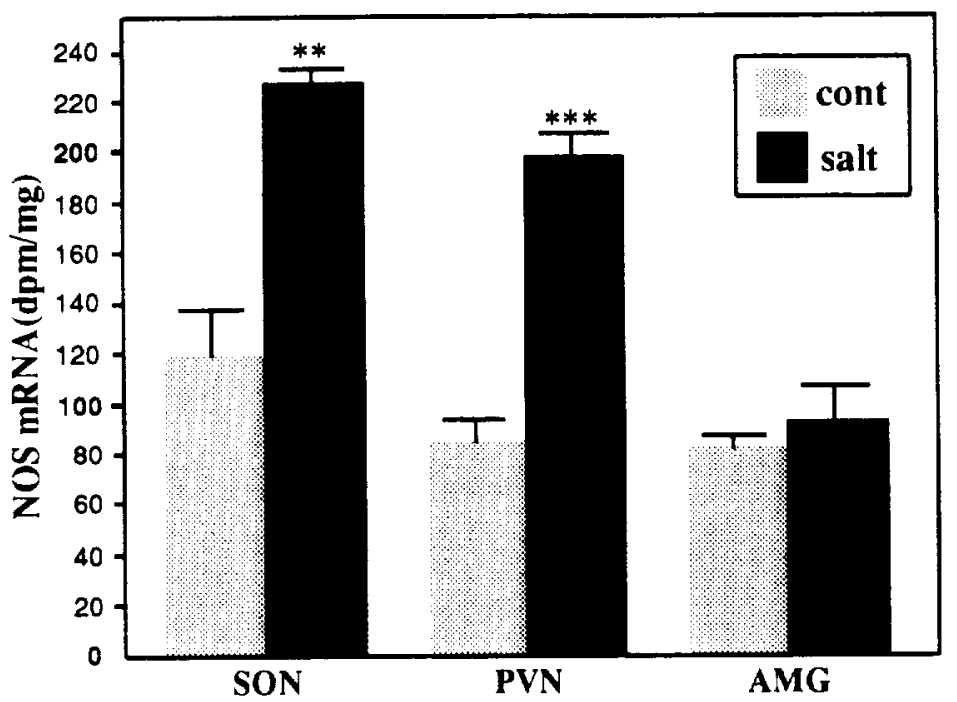

FIG. 12. Nitric oxide synthase (NOS) mRNA concentration in the supraoptic nucleus (SON), paraventricular nucleus (PVN), and central amygdaloid nucleus (AMG) of control and 4-day salt-loaded rats. Reproduced by permission from K. Kadowaki, J. Kishimoto, G. Leng, and P. C. Emson. Endocrinology 1994; 134: 1011-1017.

NADPH diaphorase staining in the supraoptic and paraventricular nuclei. The increase in nitric oxide synthase mRNA levels was apparently specific to these two hypothalamic nuclei because nitric oxide synthase mRNA levels did not change in the medial amygdaloid nucleus (Fig. 12) or in brain areas outside the hypothalamus.

The changes in hypothalamic nitric oxide synthase mRNA levels and diaphorase staining observed by Kadowaki et al. were accompanied by increases in nitric oxide synthase mRNA levels and nitric oxide synthase enzyme activity in the posterior pituitary. Intraperitoneal administration of the nitric oxide synthase inhibitor L-NNA, which is known to inhibit brain nitric oxide synthase (35), resulted in dose-related reductions in nitric oxide synthase activity in the posterior pituitary of salt-loaded rats. It also decreased the already low posterior pituitary vasopressin content (Fig. 13). In contrast, L-NNA did not alter pituitary vasopressin content in normally hydrated rats. Based on these results, Kadowaki et al. proposed that nitric oxide plays a neuromodulatory role to restrain the vasopressin response to osmotic stimulation.

\section{Rabbit}

In a recent study in this laboratory (43), we investigated the effect of inhibiting nitric oxide synthase with L-NAME on vasopressin secretion in conscious chronically prepared rabbits. The cardiovascular and endocrine effects of L-NAME are summarized in Fig. 14. Fifteen to twenty minutes after intravenous injection of L-NAME there was a twofold increase in plasma vasopressin concentration. The 


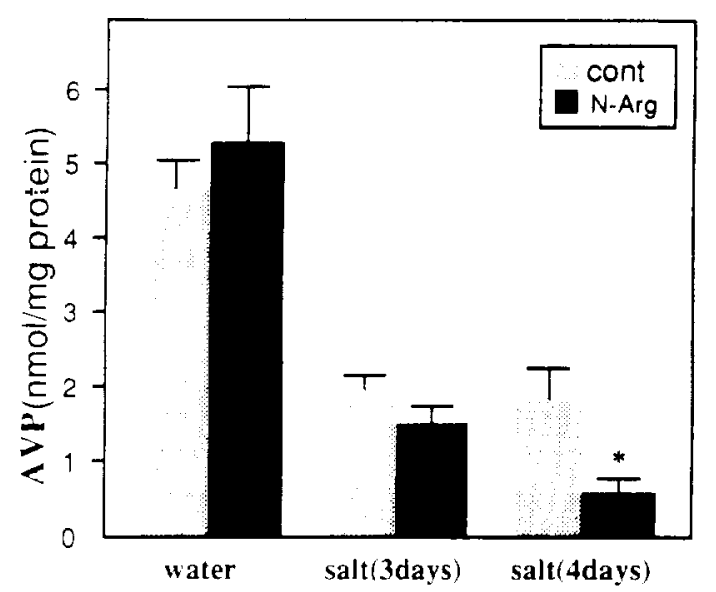

FIG. 13. Effect of the nitric oxide synthase inhibitor $N$-Arg (L-NNA) on the vasopressin content of the posterior pituitary of rats during salt loading. Reproduced by permission from K. Kadowaki, J. Kishimoto, G. Leng, and P. C. Emson. Endocrinology 1994; 134: 1011-1017.

increase in plasma vasopressin concentration was accompanied by an increase in arterial blood pressure and decreases in heart rate and plasma renin activity. This is a fairly modest increase in plasma vasopressin concentration, but two points should be considered. First, the increase occurred despite the accompanying increase in arterial pressure and decrease in plasma renin activity which would normally be expected to inhibit vasopressin secretion. Second, increases in plasma vasopressin concentration of this magnitude are sufficient to decrease urine flow (2), cause vasoconstriction (96), and inhibit renin secretion (90). Indeed, it is possible that the increase in plasma vasopressin contributed to the increase in blood pressure and decrease in plasma renin activity observed in this study. Our finding that L-NAME increased plasma vasopressin concentration is consistent with other observations described above which suggest that nitric oxide exerts a tonic inhibitory action on vasopressin secretion.

In contrast to its action on resting plasma vasopressin concentration, L-NAME did not alter the vasopressin responses to infusion of hypertonic saline or nitroprusside, nor did it alter the slope of the relationship between plasma vasopressin concentration and plasma osmolality (Fig. 15) or between plasma vasopressin concentration and mean arterial pressure. In another study (21), we observed that L-NAME did not alter the vasopressin response to hypotensive hemorrhage. Thus, although nitric oxide may be involved in the regulation of basal vasopressin secretion in the rabbit, it does not appear to participate in the vasopressin responses to acute changes in plasma osmolality, blood pressure, or blood volume. Nevertheless, in view of the observation that in rats nitric oxide synthase activity increases in the hypothalamus and pituitary during chronic salt loading (99) and dehydration (87), it will be of interest to determine if the vasopressin responses to these stimuli in rabbits are altered by inhibition of nitric oxide synthesis. 
MEAN ARTERIAL PRESSURE

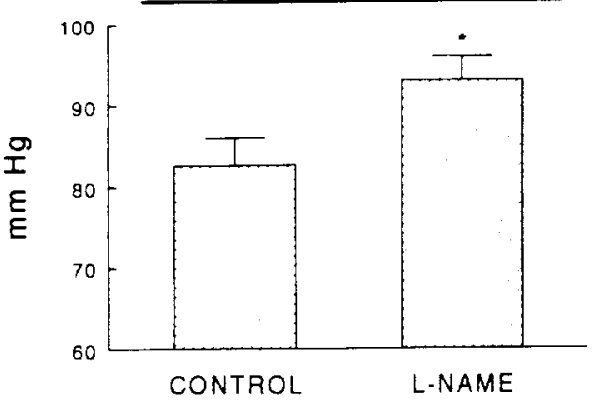

PLASMA RENIN ACTIVITY

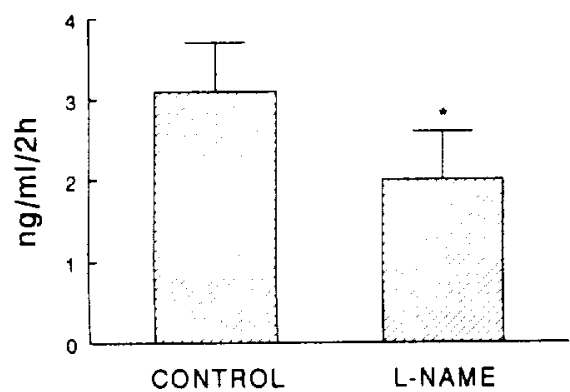

HEART RATE

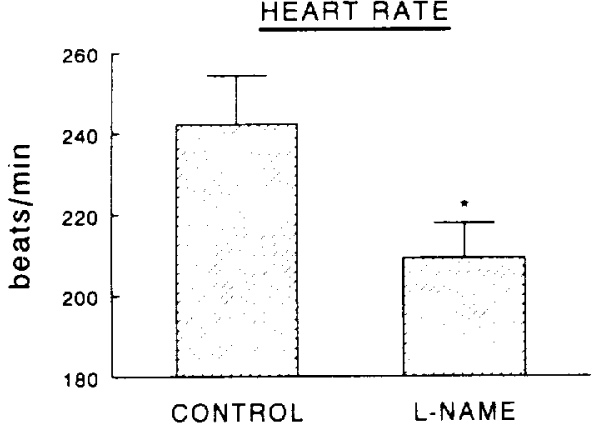

PLASMA VASOPRESSIN

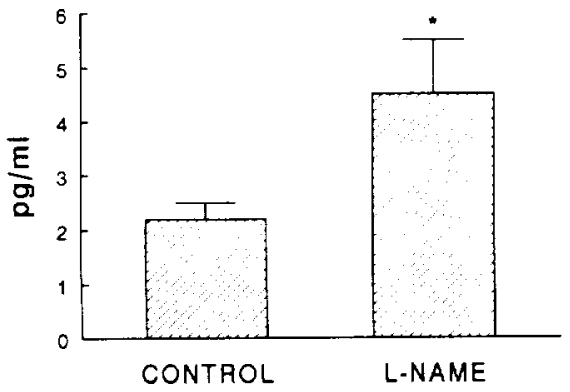

FIG. 14. Cardiovascular and endocrine effects of L-NAME infusion in conscious rabbits. Values represent the mean and SEM of observations made in eight rabbits before and 15-20 min after the start of the I-NAME infusion. ${ }^{*} p<0.05$ compared to the control value. Slightly modified from Goyer et al. (43).

$\operatorname{Dog}$

Manning et al. (73) observed that blockade of nitric oxide synthesis with L-NAME in conscious dogs caused a marked reduction in urine flow. This decrease was almost completely prevented by a vasopressin $V_{1}$ receptor antagonist. They suggested that L-NAME increased vasopressin release which in turn sequentially decreased vasa recta blood flow, renal interstitial hydrostatic pressure, and urine flow, effects which would be prevented by blockade of vasopres$\sin \mathrm{V}_{1}$ receptors (131). However, as they acknowledged, the L-NAME-induced diuresis may have resulted from changes other than increased vasopressin secretion. Indeed, Elsner et al. (36) previously reported that although blockade of nitric oxide synthesis with L-NNA decreased urine flow in conscious dogs, it did not change plasma vasopressin concentration. Thus, further investigation is required to determine the mechanism by which blockade of nitric oxide synthesis decreases urine flow, and if increases in vasopressin secretion contribute to this response.

\section{Summary: Vasopressin}

Histochemical and immunocytochemical studies have clearly established that nitric oxide synthase is present in the supraoptic and paraventricular nuclei of 


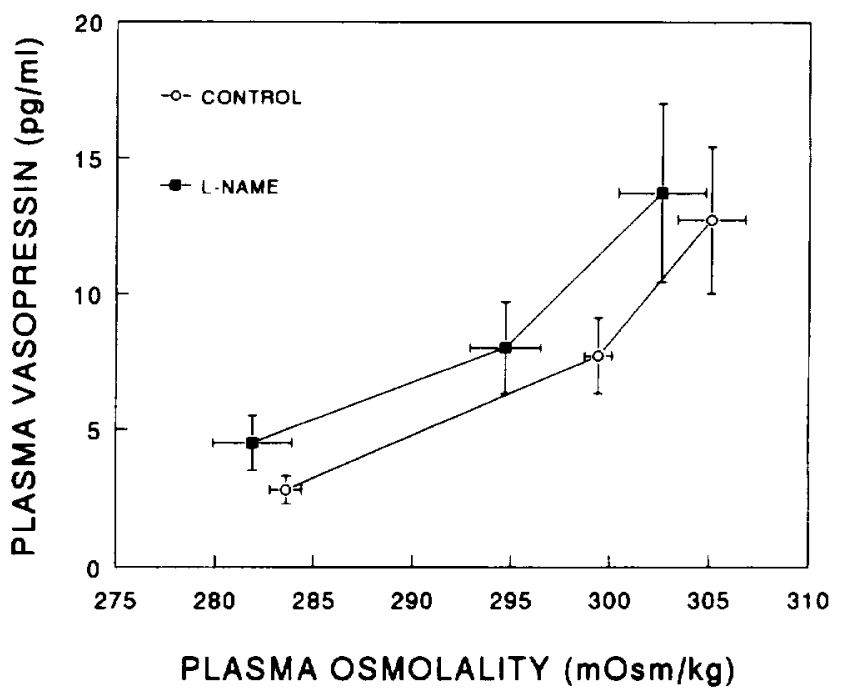

FIG. 15. Relationship between plasma vasopressin concentration and plasma osmolality in conscious rabbits under control conditions and during infusion of the nitric oxide synthase inhibitor L-NAME. Values represent the mean \pm SEM of observations made in seven rabbits. Slightly modified from Goyer et al. (43).

the hypothalamus and in the posterior pituitary. Colocalization of nitric oxide synthase and vasopressin have been demonstrated, although only in a small number of neurons. Nitric oxide synthase activity in the hypothalamus and pituitary is increased by maneuvers known to stimulate vasopressin secretion, including salt loading and dehydration. Administration of L-arginine and nitric oxide donors in vitro and in vivo have produced variable effects on vasopressin secretion but the most consistent one appears to be inhibition. Blockade of nitric oxide synthesis has been reported to increase vasopressin secretion, but again variable results have been obtained. One attractive working hypothesis proposed by Kadowaki et $a l .(60)$ is that nitric oxide serves a neuromodulatory role as an inhibitor of vasopressin secretion.

\section{ACKNOWLEDGMENTS}

Research in the author's laboratory is supported by NASA Grant NAG 2-779. The expert assistance of Lance Chou, Dina San Juan, and Laura Nunes is gratefully acknowledged.

\section{REFERENCES}

1. Arevalo R, Sanchez F, Alonso JR, Carretero J, Vazquez R, Aijon J. NADPH-diaphorase activity in the hypothalamic magnocellular neurosecretory nuclei of the rat. Brain Res Bull 1992; 28: 599-603.

2. Baerwolff M, Bie P. Effects of subpicomolar changes in vasopressin on urinary concentration. Am J Physiol 1988; 255: R940-R945. 
3. Baumann JE, Persson PB, Ehmke H, Nafz B, Kirchheim HR. Role of endothelium-derived relaxing factor in renal autoregulation in conscious dogs. Am J Physiol 1992; 263: F208-F213.

4. Beavo JA, Reifsnyder DH. Primary sequence of cyclic nucleotide phosphodiesterase isozymes and the design of selective inhibitors. TI P S 1990; 11: 150-155.

5. Beierwaltes WH, Carretero OA. Nonprostanoid endothelium-derived factors inhibit renin release. Hypertension 1992; 19: II-68-II-73.

6. Bredt DS, Glatt CE, Hwang PM, Fotuhi M, Dawson TM, Snyder SH. Nitric oxide synthase protein and mRNA are discretely localized in neuronal populations of the mammalian CNS together with NADPH diaphorase. Neuron 1991; 7: 615-624.

7. Bredt DS, Hwang PM, Snyder SH. Localization of nitric oxide synthase indicating a neural role for nitric oxide. Nature $1990 ; \mathbf{3 4 7}$ : 768-770

8. Bredt DS, Snyder SH. Nitric oxide: a physiologic messenger molecule. Annu Rev Biochem 1994; 63: 175-195.

9. Briggs JP, Lorenz JN, Weiprecht H, Schnermann J. Macula densa control of renin secretion. Renal Physiol Biochem 1991; 14: 164-174.

10. Bruhwyler J, Chleide E, Liegeois JF, Carreer F. Nitric oxide: A new messenger in the brain. Neurosci Biobehav Rev 1993; 17: 373-384.

11. Burton GA, MacNeil S, de Jonge A, Haylor J. Cyclic GMP release and vasodilation induced by EDRF and atrial natriuretic factor in the isolated perfused kidney of the rat. $B r J$ Pharmacol 1990; 99: 364-368.

12. Buxton ILO, Cheek DJ, Eckman D, Westfall DP, Sanders KM, Keef KD. $\mathrm{N}^{\mathrm{C}}$-nitro L-arginine methyl ester and other alkyl esters of arginine are muscarinic receptor antagonists. Circ Res 1993; 72: 387-395.

13. Calka J, Block CH. Angiotensin-(1-7) and nitric oxide synthase in the hypothalamoneurohypophysial system. Brain Res Bull 1993a; 30: 677-685.

14. Calka J, Block CH. Relationship of vasopressin with NADPH-diaphorase in the hypothalamoneurohypophyseal system. Brain Res Bull 1993b; 32: 207-210.

15. Calka J, Wolf G, Brosz M. Ultrastructural demonstration of NADPH-diaphorase histochemical activity in the supraoptic nucleus of normal and dehydrated rats. Brain Res Bull 1994; 34: 301-308.

16. Campbell WB, Henrich WL. Endothelial factors in the regulation of renin release. Kidney Int $1990 ; 38: 612-617$.

17. Ceccatelli S, Eriksson M. The effect of lactation on nitric oxide synthase gene expression. Brain Res 1993; 625: 177-179.

18. Ceccatelli S, Lundberg JM, Fahrenkrug J, Bredt DS, Snyder SH, Hokfelt T. Evidence for involvement of nitric oxide in the regulation of hypothalamic portal blood flow. Neuroscience 1992; 51: 769-772.

19. Chen M, Schnermann J, Malvin RL, Killen PD, Briggs JP. Time course of stimulation of renal renin messenger RNA by furosemide. Hypertension $1993 ; 21: 36-41$.

20. Chen M, Schnermann J, Smart AM, Brosius FC, Killen PD, Briggs JP. Cyclic AMP selectively increases renin mRNA stability in cultured juxtaglomerular granular cells. J Biol Chem 1993; 268: 24138-24144.

21. Chiu T, Reid IA. Effect of inhibition of nitric oxide synthesis on the cardiovascular and endocrine responses to hemorrhage in conscious rabbits. Hypertension Res, in press.

22. Churchill PC. Second messengers in renin secretion. Am J Physiol 1985; 249: F175-F184.

23. Conti M, Jin S-LC, Monaco L, Repaske DR, Swinnen JV. Hormonal regulation of cyclic nucleotide phosphodiesterases. Endocrine Rev 1991; 12: 218-234.

24. Corbett JA, Sweetland MA, Wang JL, Lancaster JR, McDaniel ML. Nitric oxide mediates cytokine-induced inhibition of insulin secretion by human islets of Langerhans. Proc Natl Acad Sci USA 1993; 90: 1731-1735. 
25. Costa A, Trainer P, Besser M, Grossman A. Nitric oxide modulates the release of corticotropinreleasing hormone from the rat hypothalamus in vitro. Brain Res 1993; 605: 187-192.

26. D'Aloia M-AE, Noble AR. L-Arginine:nitric oxide pathway could play a role in the intracellular control of renin secretion. $J$ Human Hypertension 1993; 7: 393-394.

27. Dananberg J, Sider RS, Grekin RJ. Sustained hypertension induced by orally administered nitro-L-arginine. Hypertension 1993; 21 : 359-363.

28. Davis JO, Freeman RH. Mechanisms regulating renin release. Physiol Rev 1976; 56: 1-56.

29. Della Bruna R, Kurtz A, Corvol P, Pinet F. Renin mRNA quantification using polymerase chain reaction in cultured juxtaglomerular cells: short-term effects of cAMP on renin mRNA and secretion. Circ Res 1993; 73: 639-648.

30. Deng AH, Baylis C. Locally produced EDRF controls preglomerular resistance and ultrafiltration coefficient. Am J Physiol 1993; 264: F212-F215.

31. Deng X, Welch WJ, Wilcox CS. Renal vasoconstriction during inhibition of NO synthase: Effects of dietary salt. Kidney Int 1994; 46: 639-646.

32. Denton KM, Anderson WP. Intrarenal haemodynamic and glomerular responses to inhibition of nitric oxide formation in rabbits. $J$ Physiol (London) 1994; 475: 159-167.

33. Downing GJ, Poisner R, Poisner AM. $\beta$-Adrenoceptor activation stimulates, and phosphodiesterase inhibition potentiates, placental prorenin synthesis and release. $J$ Clin Endocrinol Metab 1994; 78: 41-47.

34. Drewett JG, Garbers DL. The family of guanylyl cyclase receptors and their ligands. Endocrine Rev 1994; 15: 135-162.

35. Dwyer MA, Bredt DS, Snyder SH. Nitric oxide synthase: Irreversible inhibition by L- $N^{\mathrm{CG}_{-}}$ nitroarginine in brain in vitro and in vivo. Biochem Biophys Res Commun 1991; 176: $1136-1141$.

36. Elsner D, Muntze A, Kromer EP, Riegger GAJ. Inhibition of synthesis of endothelium-derived nitric oxide in conscious dogs. Am $J$ Hypertension 1992; 5: 288-291.

37. Eriksson S, Appelgren B, Rundgren M, Andersson B. Vasopressin release in response to intracerebroventricular $\mathrm{L}$-alanine and $\mathrm{L}$-arginine, and its dependence upon $\mathrm{CSF} \mathrm{NaCl}$ concentration. Acta Physiol Scand 1982; 116: 75-81.

38. Forstermann U, Closs EI, Pollock JS, Nakane M, Schwarz P, Gath I, Kleinert H. Nitric oxide synthase isozymes: Characterization, purification, molecular cloning, and functions. Hypertension 1994; 23: 1121-1131.

39. Ganong WF. Sympathetic effects on renin secretion; mechanism and physiological role. In: Assaykeen TA, Ed. Control of Renin Secretion. New York: Plenum, 1972: 17-32.

40. Ganong WF. Review of Medical Physiology. Connecticut: Appleton \& Lange, 1993: 216-221.

41. Gardes J, Gonzales M-F, Chatellier G, Alhenc-Gelas F, Menard J. Search for antagonists of $\mathrm{L}-N^{\mathrm{G}}$-nitro-L-arginine methyl ester-induced renal vasoconstriction and renin suppression. $J$ Hypertension 1993; 11 (Suppl. 5): S425-S426.

42. Gardes J, Poux J-M, Gonzalez M-F, Alhenc-Gelas F, Menard J. Decreased renin release and constant kallikrein secretion after injection of L-NAME in isolated perfused rat kidney. Life Sci 1992; 50: 987-993.

43. Goyer M, Bui H, Chou L, Evans J, Keil LC, Reid IA. Effect of inhibition of nitric oxide synthesis on vasopressin secretion in conscious rabbits. Am $J$ Physiol 1994; 266: H822-H828.

44. Graves J, Poston L. $\beta$-Adrenoceptor agonist mediated relaxation of rat isolated resistance arteries-A role for the endothelium and nitric oxide. Br J Pharmacol 1993; 108: 631-637.

45. Grossman A. Editorial: NO news is good news. Endocrinology 1994; 134: 1003-1005.

46. Hackenthal E, Paul M, Ganten D, Taugner R. Morphology, physiology, and molecular biology of renin secretion. Physiol Rev 1990; 70: 1067-1116.

47. Harada S, Tokunaga S, Momohara M, Masaki H, Tagawa T, Imaizumi T, Takeshita A. Inhibition of nitric oxide formation in the nucleus tractus solitarius increases renal sympathetic nerve activity in rabbits. Circ Res 1993; 72: 511-516. 
48. Haynes J, Kithas PA, Taylor AE, Strada SJ. Selective inhibition of cGMP-inhibitable cAMP phosphodiesterase decreases pulmonary vasoreactivity. Am J Physiol 1991; 261: H487H492.

49. He X-R, Greenberg SG, Schnermann JB, Briggs JP. Role of nitric oxide (NO) in regulation of macula densa mediated renin secretion. FASEB J 1993; 7: A221.

50. Henrich WL, McAllister EA, Smith PB, Campbell WB. Guanosine 3',5'-cyclic monophosphate as a mediator of inhibition of renin release. Am $J$ Physiol 1988; 255: F474-F478.

51. Heuze-Joubert I, Mennecier P, Simonet S, Laubie M, Verbeuren TJ. Effect of vasodilators, including nitric oxide, on the release of cGMP and cAMP in the isolated perfused rat kidney. Eur J Pharmacol 1992; 220: 161-171.

52. Hoffend J, Cavarape A, Endlich K, Steinhausen M. Influence of endothelium-derived relaxing factor on renal microvessels and pressure-dependent vasodilation. Am J Physiol 1993; 265: F285-F292.

53. Ito S. Role of nitric oxide in glomerular arterioles and macula densa. NIPS 1994; 9: 115-119.

54. Itoh S, Carretero OA. Role of the macula densa in the control of renin release. Hypertension 1985; 7: I-49-I-54.

55. Jackson EK. Adenosine: A physiological brake on renin release. Annu Rev Pharmacol Toxicol 1991; 31: 1-35.

56. Johns EJ, Singer B. Effect of propranolol and theophylline on renin release caused by furosemide in the cat. Eur J Pharmacol 1973; 23: 67-73.

57. Johnson RA, Freeman RH. Pressure natriuresis in rats during blockade of the L-arginine/ nitric oxide pathway. Hypertension 1992; 19: 333-338.

58. Johnson RA, Freeman RH. Sustained hypertension in the rat induced by chronic blockade of nitric oxide production. Am J Hypertension 1992, 5: 919-922.

59. Johnson RA, Freeman RH. Renin release in rats during blockade of nitric oxide synthesis. Am J Physiol 1994; 266: R1723-R1729.

60. Kadowaki K, Kishimoto J, Leng G, Emson PC. Up-regulation of nitric oxide synthase (NOS) gene expression together with NOS activity in the rat hypothalamo-hypophysial system after chronic salt loading: Evidence of a neuromodulatory role of nitric oxide in arginine vasopressin and oxytocin secretion. Endocrinology 1994; 134: 1011-1017.

61. Kato $\mathrm{M}$. Involvement of nitric oxide in growth hormone $(\mathrm{GH})$-releasing hormone-induced $\mathrm{GH}$ secretion in rat pituitary cells. Endocrinology 1992; 131: $2133-2138$.

62. Keeton TK, Campbell WB. The pharmacologic alteration of renin release. Pharmacol Rev 1980; 32: 81-227.

63. Kerwin JF, Heller M. The arginine-nitric oxide pathway: A target for new drugs. Med Res Rev 1994; 14: 23-74.

64. Klabunde RE, Kimber ND, Kuk JE, Helgren MC, Forstermann U. $N^{\mathrm{G}}$-methyl-L-arginine decreases contractility, cGMP and cAMP in isoproterenol-stimulated rat hearts in vitro. Eur $J$ Pharmacol 1992; 223: 1-7.

65. Knowles RG, Moncada S. Nitric oxide synthases in mammals. Biochem $J$ 1994; 298: 249-258.

66. Kurtz A. Cellular control of renin secretion. Rev Physiol Biochem Pharmacol 1989; 113:2-40.

67. Kurtz A, Kaissling B, Busse R, Baier W. Endothelial cells modulate renin secretion from isolated mouse juxtaglomerular cells. I Clin Invest 1991; 88: 1147-1154.

68. LaPointe J-Y, Bell PD, Cardinal J. Direct evidence for apical $\mathrm{Na}^{+}: 2 \mathrm{Cl}^{-}: \mathrm{K}^{+}$cotransport in macula densa cells. Am J Physiol 1990; 258: F1466-F1469.

69. Liu L, Barajas L. Nitric oxide synthase immunoreactive neurons in the rat kidney. Neurosci Lett 1993; 161: 145-148.

70. Lowenstein CJ, Dinerman JL, Snyder SH. Nitric oxide: A physiologic messenger. Ann Int Med 1994; 120: 227-237.

71. Lutz-Bucher B, Koch B. Evidence for an inhibitory effect of nitric oxides on neuropeptide secretion from isolated neural lobe of the rat pituitary gland. Neurosci Lett 1994; 165: 48-50. 
72. Majid DSA, Williams A, Navar LG. Inhibition of nitric oxide synthesis attenuates pressureinduced natriuretic responses in anesthetized dogs. Am J Physiol 1993; 264: F79-F87.

73. Manning RD, Hu L, Williamson TD. Mechanisms involved in the cardiovascular-renal actions of nitric oxide inhibition. Hypertension 1994; 23: 951-956.

74. Masuoka H, Ito M, Nakano T, Naka M, Tanaka T. Effects of aminrone and enoximone on the subclasses of cyclic AMP phosphodiesterase from human heart and kidney. $J$ Cardiovasc Pharmacol 1990; 15: 302-307.

75. Meyer P, Menard J, Papanicolaou N, Alexandre J-M, Devaux C, Milliez P. Mechanism of renin release following furosemide diuresis in the rabbit. Am $J$ Physiol 1968; 215: 908-915.

76. Miyagawa A, Okamura H, Ibata Y. Coexistence of oxytocin and NADPH-diaphorase in magnocellular neurons of the paraventricular and the supraoptic nuclei of the rat hypothalamus. Neurosci Lett 1994; 171 : 13-16.

77. Moncada S, Palmer RMJ, Higgs EA. Nitric oxide: Physiology, pathophysiology, and pharmacology. Pharmacol Rev 1991; 43: 109-142.

78. Morris SM, Billiar TR. New insights into the regulation of inducible nitric oxide synthesis. Am J Physiol 1994; 266: E829-E839.

79. Mundel P, Bachmann S, Bader M, Fischer A, Kummer W, Mayer B, Kriz W. Expression of nitric oxide synthase in kidney macula densa cells. Kidney Int 1992; 42: 1017-1019.

80. Munter $\mathrm{K}$, Hackenthal $\mathrm{E}$. The participation of the endothelium in the control of renin release. J Hypertension 1991; 9: S236-S237.

81. Murray KJ. Methods in cyclic nucleotide research. In: Boulton AA, Baker GB, Taylor CW, Eds. Intracellular Messengers. New Jersey: Humana Press, 1992: 313-368.

82. Naess PA, Christensen G, Kirkeboen KA, Kiil F. Effect on renin release of inhibiting renal nitric oxide synthesis in anaesthetized dogs. Acta Physiol Scand 1993; 148: 137-142.

83. Ota M, Crofton JT, Festavan GT, Share L. Evidence that nitric oxide can act centrally to stimulate vasopressin release. Neuroendocrinology 1993; 57: 955-959.

84. Pang DC. Cyclic AMP and cyclic GMP phosphodiesterases: target for drug development. Drug Dev Res 1988; 12: 85-92

85. Peart WP, Quesada T, Tenyi I. The effects of cyclic adenosine $3^{\prime}, 5^{\prime}$-monophosphate and guanosine $3^{\prime}, 5^{\prime}$-monophosphate and theophylline on renin secretion in the isolated perfused kidney of the rat. Br J Pharmacol 1975; 54: 55-60.

86. Persson PB, Baumann JE, Ehmke H, Hackenthal E, Kirchheim HR, Nafz B. Endotheliumderived NO stimulates pressure-dependent renin release in conscious dogs. Am J Physiol 1993; 264: F943-F947.

87. Pow DV. NADPH-diaphorase (nitric oxide synthase) staining in the rat supraoptic nucleus is activity-dependent: Possible functional implications. J Neuroendocrinol 1992; 4: 377-380.

88. Raij L. Nitric oxide and the kidney. Circulation 1993; 87: 26-29.

89. Rees DD, Palmer RMJ, Schulz R, Hodson HF, Moncada S. Characterization of three inhibitors of endothelial nitric oxide synthase in vitro and in vivo. $B r J$ Pharmacol 1990; 101: 746-752.

90. Reid IA. Inhibition of renin secretion by vasopressin: Mechanisms and physiological role. In: Schrier RW, Ed. Vasopressin. New York: Raven Press, 1985: 21-28.

91. Reid IA, Bui $\mathrm{H}$, Chou L. Role of nitric oxide in the renin and heart rate responses to beta adrenergic stimulation. Hypertension 1994; 23 (Suppl. I): I-49-I-53.

92. Reid IA, Chiu T. Role of phosphodiesterase III in the suppression of renin secretion by inhibition of nitric oxide synthesis. $J$ Hypertension 1994; 12(Suppl. 3): S33.

93. Reid IA, Chiu T, Chou L. Effect of inhibition of type III phosphodiesterase on renin secretion in conscious rabbits. Abstracts, International Conference on the Biochemistry and Molecular Biology of Nitric Oxide, UCLA 1994: 100.

94. Reid IA, Chou L. Role of nitric oxide in macula densa stimulation of renin secretion. Hypertension 1993; 22: 444. 
95. Reid IA, Morris BJ, Ganong WF. The renin-angiotensin system. Annu Rev Physiol 1978; 40: 377-410.

96. Reid IA, Schwartz J. Role of vasopressin in the control of blood pressure. Front Neuroendocrinol 1984; 8: 177-197.

97. Ribeiro MO, Antunes E, de Nucci G, Lovisolo SM, Zatz R. Chronic inhibition of nitric oxide synthesis: A new model of arterial hypertension. Hypertension 1992; 20: 298-303.

98. Rivier C, Shen GH. In the rat, endogenous nitric oxide nodulates the response of the hypothalamic-pituitary-adrenal axis to interleukin-1 $\beta$, vasopressin, and oxytocin. $J$ Neurosci 1994; 14: 1985-1993.

99. Sagar SM, Ferriero DM. NADPH diaphorase activity in the posterior pituitary: Relation to neuronal function. Brain Res 1987; 400: 348-352.

100. Sakuma I, Togashi H, Yoshioka M, Saito H, Yanagida M, Tamura M, Kobayashi T, Yasuda H, Gross SS, Levi R. $N^{\mathrm{G}}$-methyl-L-arginine, an inhibitor of L-arginine-derived nitric oxide synthesis, stimulates renal sympathetic nerve activity in vivo. A role for nitric oxide in the central regulation of sympathetic tone? Circ Res 1992; 70: 607-611.

101. Salazar FJ, Pinilla JM, Lopez F, Romero JC, Quesada T. Renal effects of prolonged synthesis inhibition of endothelium-derived nitric oxide. Hypertension 1992; 20: 113-117.

102. Salom MG, Lahera V, Miranda-Guardiola F, Romero JC. Blockade of pressure natriuresis induced by inhibition of renal synthesis of nitric oxide in dogs. Am $J$ Physiol 1992; 262: F718-F722.

103. Salomonsson M, Gonzalez E, Westerlund P, Persson AE. Intracellular cytosolic free calcium concentration in the macula densa and in ascending limb cells at different luminal concentrations of sodium chloride and with added furosemide. Acta Physiol Scand 1991; 142: 383-290.

104. Salomonsson M, Skott O, Persson AEG. Lack of effect of intraluminal pressure on renin release from isolated afferent arterioles. Pflugers Arch 1992; 421: 466-468.

105. Sanchez F, Alonso JR, Arevalo R, Blanco E, Aijon J, Vazquez R. Coexistence of NADPHdiaphorase with vasopressin and oxytocin in the hypothalamic magnocellular neurosecretory nuclei of the rat. Cell Tissue Res 1994; 276: $31-34$.

106. Schlatter E, Salomonsson M, Persson AEG, Greger R. Macula densa cells sense luminal NaCl concentration via furosemide sensitive $\mathrm{Na}^{+} 2 \mathrm{Cl}^{-} \mathrm{K}^{+}$cotransport. Pflugers Arch 1989; 414: $286-290$.

107. Schmidt HHHW, Warner TD, Ishii K, Sheng H, Murad F. Insulin secretion from pancreatic B cells caused by L-arginine-derived nitrogen oxides. Science 1992; 255: 721-723.

108. Scholz H, Kurtz A. Involvement of endothelium-derived relaxing factor in the pressure control of renin secretion from isolated perfused kidney. $J$ Clin Invest 1993; 91: 1088-1094.

109. Schricker K, Kurtz A. Liberators of NO exert a dual effect on renin secretion from isolated mouse renal juxtaglomerular cells. Am J Physiol 1993; 265: F180-F186.

110. Schricker K, Ritthaler T, Kramer BK, Kurtz A. Effect of endothelium-derived relaxing factor on renin secretion from isolated mouse renal juxtaglomerular cells. Acta Physiol Scand 1993; 149: $347-354$

111. Schuman EM, Madison DV. Nitric oxide and synaptic function. Annu Rev Neurosci 1994; 17: $153-183$

112. Sigmon DH, Carretero OA, Beierwaltes WH. Endothelium-derived relaxing factor regulates renin release in vivo. Am J Physiol 1992; 263: F256-F261.

113. Siragy HM. Endothelium-derived relaxing factor modulates renal interstitial cyclic GMP. $J$ Cardiovasc Pharmacol 1992; 20: S163-S165.

114. Skott O, Jensen BL. Cellular and intrarenal control of renin secretion. Clin Sci 1993; 84: 1-10.

115. Sortino MA, Aleppo G, Scapagnini U, Canonico PL. Involvement of nitric oxide in the regulation of gonadotropin-releasing hormone release from the GT1-1 neuronal cell line. Endocrinology 1994; 134: 1782-1787. 
116. Summy-Long JY, Bui V, Mantz S, Koehler E, Weisz J, Kadekaro M. Central inhibition of nitric oxide synthase preferentially augments release of oxytocin during dehydration. Neurosci Lett 1993; 152: 190-193.

117. Tabor BL, Godfrey C, Strong MH, Wilkins FC, Granger JP. Intrarenal nitric oxide (NO) synthesis inhibition increases renin secretion rate. FASEB J 1994; 8: A579.

118. Terada Y, Tomita K, Nonoguchi H, Marumo F. Polymerase chain reaction localization of constitutive nitric oxide synthase and soluble guanylyl cyclase messenger RNAs in microdis. sected rat nephron segments. I Clin Invest 1992; 90: 659-665.

119. Tojo A, Gross SS, Zhang L, Tisher CC, Schmidt HHHW, Madsen KM, Wilcox CS. Immunocytochemical localization of distinct isoforms of nitric oxide synthase in the juxtaglomerular apparatus of normal rat kidney. J Am Soc Nephrol 1994; 4: 1438-1447.

120. Tolins JP, Shultz PJ. Endogenous nitric oxide synthesis determines sensitivity to the pressor effect of salt. Kidney Int 1994; 46: 230-236.

121. Torres G, Lee S, Rivier C. Ontogeny of the rat hypothalamic nitric oxide synthase and colocalization with neuropeptides. Mol Cell Neurosci 1993; 4: 155-163.

122. Tracey WR, Pollock JS, Murad F, Nakane M, Forstermann U. Identification of an endotheliallike type III NO synthase in LLC-PK ${ }_{1}$ kidney epithelial cells. Am J Physiol 1994; 266: C22-C28.

123. Tsukahara H, Krivenko Y, Moore LC, Goligorsky MS. Decrease in ambient |Cl-| stimulates nitric oxide release from cultured rat mesangial cells. Am J Physiol 1994; 267: F190-F195.

124. Vander AJ. Control of renin release. Physiol Rev 1967; 47: 359-382.

125. Vidal MJ, Romero JC, Vanhoutte PM. Endothelium-derived relaxing factor inhibits renin release. Eur J Pharmacol 1988; 149: 401-402

126. Villar MJ, Ceccatelli S, Bedecs K, Bartfai T, Bredt D, Snyder SH, Hokfelt 'T. Upregulation of nitric oxide synthase and galanin message-associated peptide in hypothalamic magnocellular neurons after hypophysectomy. Immunohistochemical and in situ hybridization studies. Brain Res 1994; 650: 219-228.

127. Wang Y-X, Poon KS, Randall DJ, Pang CCY. Endothelium-derived nitric oxide partially mediates salbutamol-induced vasodilatations. Eur J Pharmacol 1993; 250: 335-340.

128. Warren JB, Pons F, Brady AJB. Nitric oxide biology: Implications for cardiovascular therapeuties. Cardiovase Res 1994; 28: 25-30.

129. Wilcox CS, Welch WJ, Murad F, Gross SS, Taylor G, Levi R, Schmidt HHHW. Nitric oxide synthase in macula densa regulates glomerular capillary pressure. Proc Natl Acad Sci USA 1992; 89: 11993-11997.

130. Yasin S, Costa A, Trainer P, Windle R, Forsling ML, Grossman A. Nitric oxide modulates the release of vasopressin from rat hypothalamic explants. Endocrinology 1993; 133: 1466-1469.

131. Zimmerhackl B, Robertson CR. Jamison RL. Effect of arginine vasopressin on renal medullary blood flow: A videomicroscopic study. J Clin Invest 1985; 76: 770-778. 
- 